\title{
Marasmius (Basidiomycota - Marasmiaceae) do Parque Estadual das Fontes do Ipiranga, São Paulo, SP, Brasil: seção Sicci
}

\author{
Carla Puccinelli ${ }^{1}$ e Marina Capelari ${ }^{1,2}$
}

Recebido: 05.03.2009; aceito: 06.11.2009

\begin{abstract}
Marasmius (Basidiomycota - Marasmiaceae) from Parque Estadual das Fontes do Ipiranga, São Paulo, SP, Brazil: section Sicci). Fourteen species of Marasmius section Sicci from Parque Estadual das Fontes do Ipiranga (PEFI) are described, illustrated and commented. Identifications keys for the taxa of series Atrorubentes, Haematocephali and Leonini are also presented. The species $M$. aff. pseudoniveus and M. bellus are cited for the first time for PEFI; M. bambusiniformis and M.ferrugineus for the first time for São Paulo State and M. congregatus and M. musicola for the first time from Brazil. Key-words: Agaricales, Atlantic Rainforest, diversity, taxonomy
\end{abstract}

RESUMO - (Marasmius (Basidiomycota - Marasmiaceae) do Parque estadual das Fontes do Ipiranga, São Paulo, SP, Brasil: seção Sicci). São descritas, ilustradas e comentadas catorze espécies de Marasmius seção Sicci, do Parque Estadual das Fontes do Ipiranga (PEFI). São apresentadas chaves de identificação para os táxons das séries Atrorubentes, Haematocephali e Leonini. As espécies de $M$. aff. pseudoniveus e M. bellus são citadas pela primeira vez para o PEFI; M. bambusiniformis e M. ferrugineus pela primeira vez para o estado de São Paulo e M. congregatus e M. musicola pela primeira vez para o Brasil. Palavras chave: Agaricales, diversidade, Mata Atlântica, taxonomia

\section{Introdução}

O gênero Marasmius Fr. é um dos principais componentes da micota tropical e são encontrados em abundância em florestas de clima úmido como a Mata Atlântica (Puccinelli \& Capelari 2006, 2007, 2009). Marasmius é caracterizado pelos basidiomas pequenos a médios, normalmente membranáceos, estipe filiforme, quase sempre de coloração escura, com micélio basal presente ou com o estipe inserido diretamente no substrato e, ao microscópio, pela superfície pilear himeniforme formada por elementos típicos para o gênero, dos tipos Globulares, Siccus e Rotalis e pelos basidiósporos lacrimóides e hialinos. Neste trabalho são consideradas as espécies da seção Sicci em continuidade ao trabalho anteriormente publicado (Puccinelli \& Capelari 2009) sobre as espécies do gênero Marasmius presentes no Parque Estadual das Fontes do Ipiranga (PEFI).

A seção Sicci Singer é a mais representativa no PEFI devido também ao fato de ser a seção com o maior número de espécies do gênero o que lhe garante uma diversidade imensa de características morfológicas. Está subdividida em subseções e séries de acordo com algumas características morfológicas como amiloidia da trama da lamela e presença ou ausência de pleurocistídios, caulocistídios e setas (Singer 1986).

As principais características diagnósticas deste grupamento taxonômico, quando observado em campo, são a base do estipe não inserido ao substrato com micélio basal, lamelas na maioria das vezes livres podendo também ser adnatas e píleo frequentemente sulcado e plissado. Microscopicamente apresentam a superfície pilear composta por elementos do tipo Siccus, às vezes intercalados com setas ou estruturas globulares (Singer 1986).

Em relação ao conhecimento prévio do gênero no PEFI, das 20 espécies já relacionadas, 13 pertencem a esta seção, M. atrorubens (Berk.) Berk. (Pegler 1997), M. berteroi (Lév.) Murrill, M. dennisii Singer (Grandi et al. 1984, Pegler 1997), M. haediniformis Singer (Pegler 1997), M. haematocephalus (Mont.) Fr. (Bononi et al. 1981, Grandi et al. 1984, Pegler 1997), M. hypophaeus Berk. \& M.A. Curtis, M. leoninus Berk., M. phaeus Berk. \& M.A. Curtis, $M$. pusio Berk. \& M.A. Curtis, M. rhabarbarinus Berk. (Pegler 1997), M. rhodocephalus (Fr.) Pat. (Bononi

1. Instituto de Botânica, Seção de Micologia e Liquenologia, Caixa Postal 3005, 01061-970 São Paulo, SP, Brasil

2. Autora para correspondência: mcapelariibot@yahoo.com 
et al. 1981), M. ruber Singer e M. subrotula Murrill (Grandi et al. 1984).

\section{Material e métodos}

O Parque Estadual das Fontes do Ipiranga (PEFI) é um dos mais significativos remanescentes de Mata Atlântica em área urbana do país. Está situado na região sul da cidade de São Paulo (2339'S e $46^{\circ} 37^{\prime} \mathrm{W}$ ), com altitude média entre 770 e $825 \mathrm{~m}$ e ocupando uma área total de 526,38 ha (Barbosa et al. 2002, Fernandes et al. 2002).

As coletas no PEFI foram iniciadas em fevereiro de 2004 e realizadas aleatoriamente em todos os meses do ano, ocorrendo com mais frequencia nos meses de primavera e verão (período chuvoso) e finalizadas em março de 2006, porém alguns materiais coletados posteriormente também foram estudados. Foram utilizadas trilhas já abertas dentro do parque, principalmente nas áreas do Jardim Botânico e do Instituto de Botânica.

O material coletado foi descrito ainda fresco e em seguida colocado em estufa com circulação de ar a $50{ }^{\circ} \mathrm{C}$ por um período máximo de $24 \mathrm{~h}$ para secagem. Para visualização das microestruturas foram realizados cortes a mão livre do material seco, rehidratado em álcool $70 \%$ e montados entre lâmina e lamínula com KOH $5 \%$ e reagente de Melzer para observação da reação de amiloidia. As observações e desenhos das microestruturas foram feitos utilizando microscópio Olympus BX50 com câmara clara acoplada, com um aumento de 800 vezes. As medidas representam os valores extremos (mínimos e máximos) de cada estrutura medida em $\mathrm{KOH}$ 5\%, o Qm (média de Q), representa a relação entre o comprimento e a largura dos basidiósporos e n o número de basidiósporos medidos.

Os exemplares pertencentes ao gênero Marasmius coletados anteriormente no parque por outros coletores e que estão depositados no herbário SP também foram estudados, quando continham informações e material suficiente para reidentificação.

\section{Resultados e Discussão}

Com as coletas recentemente realizadas, seis espécies estão sendo citadas pela primeira vez para o PEFI: M. bambusiniformes Singer, M. bellus Berk., M. congregatus Mont., M. ferrugineus (Berk.) Berk. \& M.A. Curtis, M. musicola Murrill e M. aff. pseudoniveus Singer.

Com a revisão das exsicatas, depositadas no herbário SP, foi constatado que as espécies Marasmius phaeus e $M$. pusio encontram-se desaparecidas e que as exsicatas de $M$. ruber e $M$. rhabarbarinus são fragmentos pequenos e contaminados por fungos, bem como a exsicata de $M$. haediniformis, o que tornou impossível a observação destes materiais. Portanto M. haediniformis, M. phaeus, M. pusio e $M$. ruber não estão sendo considerados neste trabalho e, também, não foram novamente coletados no PEFI. Marasmius rhabarbarinus foi recoletado e estudado. Foi constatado que a exsicata identificada como $M$. rhodocephalus trata-se, na verdade, de $M$. haematocephalus, espécie muito comum, que inclui $M$. rhodocephalus como sinônimo.

Chave de identificação para as séries da seção Sicci Singer, subseção Siccini Singer

1. Estipe glabro; caulocistídios ausentes

2. Pleurocistídios ausentes série Leonini

2. Pleurocistídios presentes série Haematocephali

1. Estipe pruinoso; caulocistídios presentes série Atrorubentes

Chave de identificação para as espécies da série Atrorubentes Desjardin \& Horak do PEFI

1. Superfície pilear composta exclusivamente de equinídios do tipo Siccus M. atrorubens

1. Superfície pilear composta de equinídios do tipo Siccus e células do tipo Globulares

2. Píleo branco a branco-sujo M. congregatus

2. Píleo creme-amarelado M. aff. pseudoniveus 
Marasmius atrorubens (Berk.) Berk., Hooker's Journ. Bot. 8: 137. 1856 = Agaricus atrorubens Berk., London J. Bot. 1: 138. 1842.

Figura 1 a-e

Píleo campanulado a convexo, laranjaavermelhado a laranja-amarronzado com papila central mais escura, margem lisa, glabro, sulcado, 1-12 mm diâm. Lamelas adnatas, não colariadas, creme a creme-alaranjadas, subdistantes, margem concolor com o píleo, com lamélulas. Estipe central, filiforme, castanho-alaranjado, clareando no ápice, onde é concolor com as lamelas, pruinoso, oco, micélio basal creme-amarelado, 15-45 mm compr. Contexto fino, creme. Basidiósporos clavado-fusiformes, algumas vezes apresentando um dos lados aplanado, hialinos, lisos, inamilóides, parede fina, 13,7-21 (-23) × 3,5-3,7 $\mu \mathrm{m}(\mathrm{Qm}=4,9 ; \mathrm{n}=30)$. Basídios clavados, hialinos, tetraesporados. Cistidíos fusóides a mucronados no ápice, alguns com parede fina, 19-29 × 5-7,5 $\mu \mathrm{m}$. Queilocistídios dimórficos, alguns semelhantes aos equinídios da superfície pilear, porém hialinos e com número reduzido de sétulas e alguns semelhantes aos cistídios 7,5-23 × 2,5-7,5 um e sétulas apicais 2,5-7,5 um compr. Trama da lamela hialina, dextrinóide, com hifas hialinas, de parede fina, septadas, com ansas, 2,5-3,7 um diâm. Superfície pilear himeniforme com equinídios do tipo Siccus, marrom-dourados e hialinos quando observados individualmente; equinídios com corpo principal 8,7-23 × 5-6,2 $\mu \mathrm{m}$ e sétulas 3,7-6,2 $\mu \mathrm{m}$ compr. Caulocistídios setiformes, amarronzados, parede espessa, 64-220 × 5-10 $\mu \mathrm{m}$. Basidioma gregário a disperso sobre folhas secas.

Material examinado: BRASIL. São Paulo: São Paulo, Parque Estadual das Fontes do Ipiranga, 16-24-I-1987, D.N. Pegler et al. s.n. (SP214514, SP214515); 2-II-2004, C. Puccinelli 6 (SP); 2-II2004, C. Puccinelli 8 (SP); 2-II-2004, C. Puccinelli 10 (SP); 19-I-2005, C. Puccinelli 66 (SP); 19-I-2005, C. Puccinelli 67 (SP).

Esta espécie é, macroscopicamente, bem caracterizada pela coloração do píleo e das lamelas e pelo estipe pruinoso. Ao microscópio pela presença
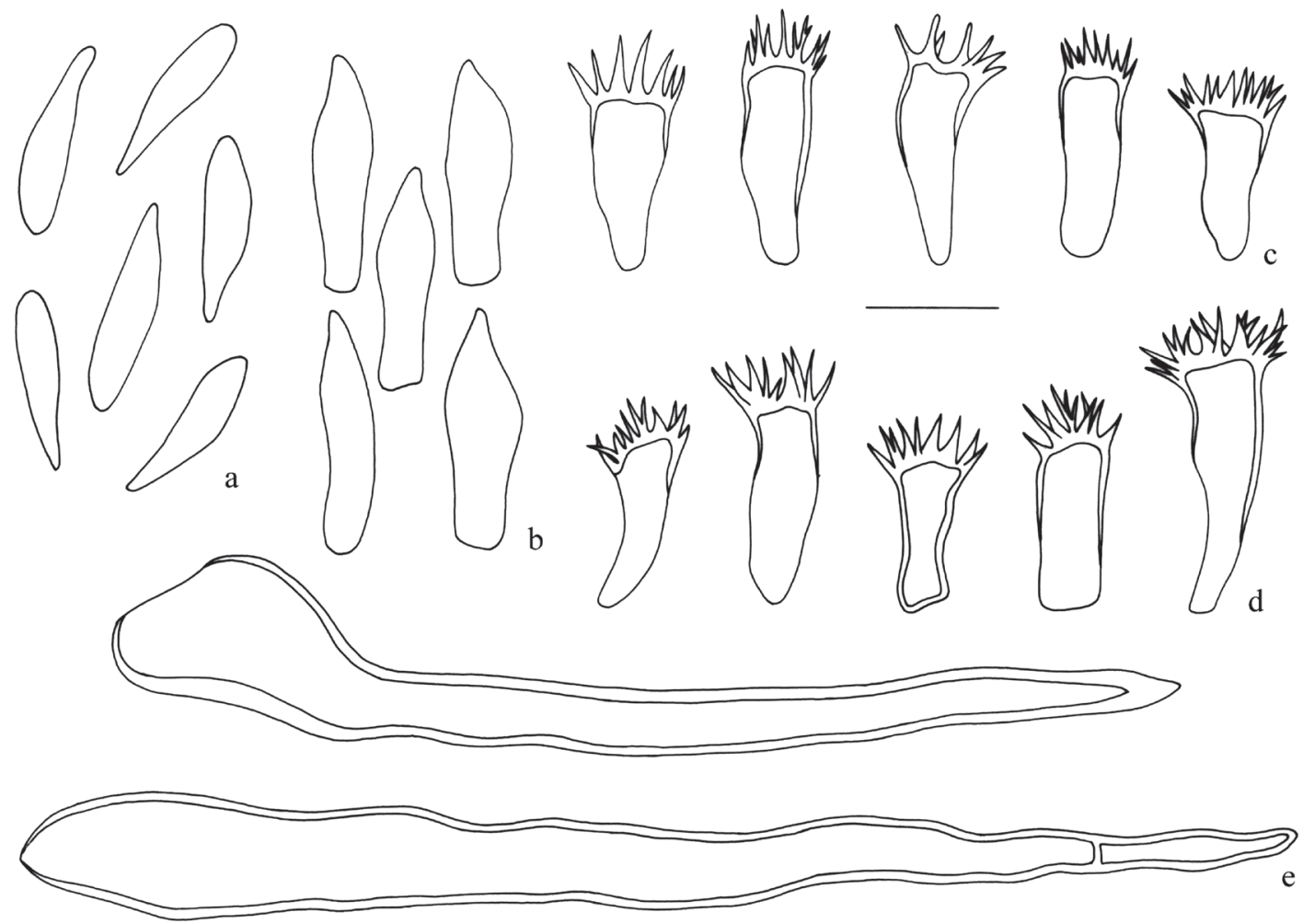

Figura 1. Marasmius atrorubens. a. Basidiósporos. b. Cistídios. c. Queilocistídios. d. Superfície pilear. e. Caulocistídios. Barra = 10 um.

Figure 1. Marasmius atrorubens. a. Basidiospores. b. Cystidia. c. Cheilocystidia. d. Pileipellis. e. Caulocystidia. Bar $=10 \mu \mathrm{m}$. 
de cistídios de formato fusóide e mucronado. O termo cistídio está empregado aqui no sentido de Singer (1965), porém alguns autores (Pegler 1977, 1983) denominaram essas estruturas de basidíolos ou cistidíolos. Em Singer (1976), a espécie foi subdividida em três variedades, baseadas, principalmente, na presença ou ausência de cistídios, mas nos comentários e com observações feitas no material tipo, Singer (1976) comentou que há dúvidas com relação à presença ou ausência de cistídios, e da dificuldade para distinguir cistidíolos de basidíolos. Nas descrições de Pegler (1977, 1983), o tamanho dos basidiósporos, de 10-15 × 2,5-3,8 um, não coincide com as do material estudado, mas concordam com as medidas descritas por Singer (1965).

A distribuição geográfica da espécie abrange Camarões (Mossebo \& Antonín 2004), Bolívia (Singer 1965, 1976), Costa Rica (Ovrebo 1996), Guadalupe (Singer 1965, 1976), Martinica (Pegler 1983), Suriname (Singer 1965, 1976, Pegler 1977), Sri Lanka (Petch 1948), Uganda (Pegler 1977), Tanzânia (Pegler 1977), Trinidad (Pegler 1983), Venezuela (Singer 1965, 1976, Dennis 1970) e no Brasil ocorre no estado de São Paulo (Pegler 1997).

As espécies M.castaneus Mont., M.jamaicensis Murrill e M.portoricensis Murrill são provavelmente, de acordo com Singer (1976) sinônimos de $M$. atrorubens.

Marasmius congregatus Mont, Ann. Sci. Nat. Bot. 4: $113,1854$.

Figura $2 \mathrm{a}-\mathrm{c}$

Píleo convexo-campanulado a quase aplanado quando maduro, branco a branco-sujo com centro creme a creme-amarelado, centro liso, levemente sulcado-reticulado, glabro, higrófano, translúcido, 21-40 mm diâm. Lamelas adnexas, não colariadas, brancas a creme, próximas a subdistantes, margem concolor, com duas séries de lamélulas. Estipe central, cilíndrico, castanho-avermelhado a marromalaranjado, tornando-se concolor com as lamelas no ápice, liso, com pubescência quase imperceptível, concentrada principalmente na base; micélio basal branco a creme bem desenvolvido, 45-65 × 1 $\mathrm{mm}$. Contexto muito fino, branco. Basidiósporos subfusóides a elipsóides, hialinos, lisos, inamilóides, parede fina, 6,2-10 × 2,7-3,7 $\mu \mathrm{m}(\mathrm{Qm}=2,3 ; \mathrm{n}=$ 12). Basídios clavados, tetraesporados, 16,2-18,7 $\times$ 3,7-5 $\mu \mathrm{m}$. Basidíolos fusóides. Pleurocistídios ausentes. Queilocistídios semelhantes aos equinídios

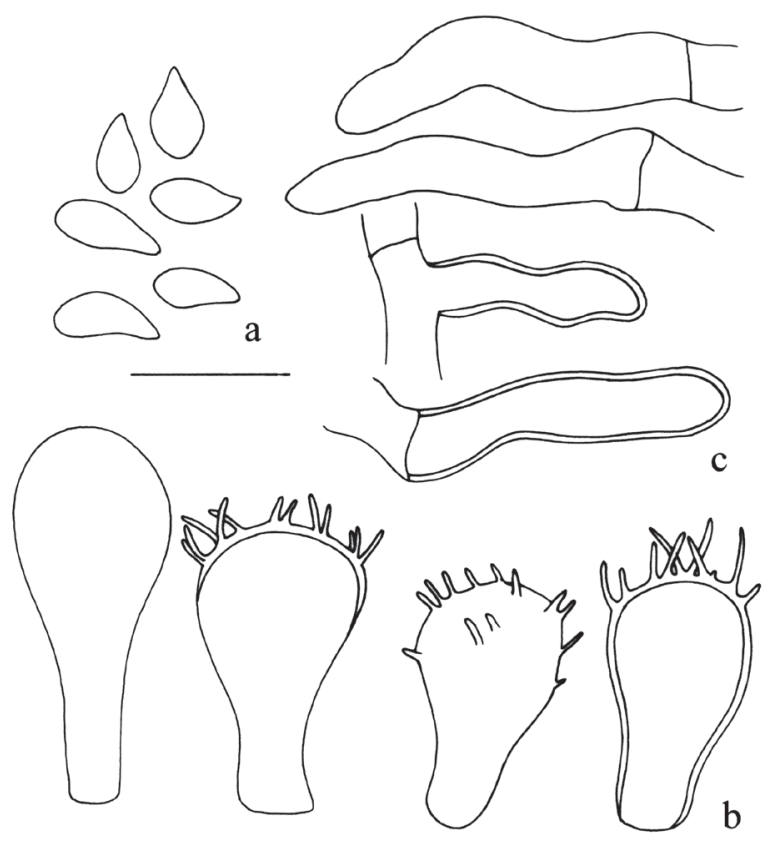

Figura 2. Marasmius congregatus. a. Basidiósporos. b. Superfície pilear. c. Caulocistídios. Barra $=10 \mu \mathrm{m}$.

Figure 2. Marasmius congregatus. a. Basidiospores. b. Pileipellis. c. Caulocystidia. Bar $=10 \mu \mathrm{m}$.

da superfície pilear com células lisas e com sétulas apicais. Trama da lamela regular, dextrinóide, com hifas hialinas, parede fina, septadas, com ansas 1,5-5 um diâm. Superfície pilear himeniforme, composta de dois tipos de estruturas: a) do tipo Globulares, clavadas a piriformes, hialinas, inamilóides, parede fina, 16,2-30 $\mu \mathrm{m} \times 8,7-15 \mu \mathrm{m}$; b) do tipo Siccus, corpo principal clavado-piriforme, hialino, 15-23 $\times$ 3,7-11,2 $\mu \mathrm{m}$, com sétulas apicais 2,5-6,2 $\mu \mathrm{m}$ compr. Caulocistídios cilíndrico-versiformes, presentes na base do estipe, 16,2-36 × 3,7-4,7 $\mu \mathrm{m}$. Basidioma gregário a disperso sobre folhas e gravetos na serapilheira.

Material examinado: BRASIL. São PAULO: São Paulo, Parque Estadual das Fontes do Ipiranga, 19-III-2003, $M$. Capelari 4239 (SP); 19-III-2003, M. Capelari 4241 (SP); 19-I-2005, C. Puccinelli 72 (SP); 8-II-2006, C. Puccinelli 176 (SP); 23-III-2006, C. Puccinelli 190 (SP).

Marasmius congregatus é caracterizado pelo píleo branco com centro creme-amarelado de contexto muito fino e translúcido, estipe ligeiramente pubescente na base e hábito gregário sobre folhas e gravetos na serapilheira. Microscopicamente pelos basidiósporos pequenos e superfície pilear formada 
por equinídios do tipo Siccus e células lisas do tipo Globulares.

Esta espécie foi originalmente descrita por Montagne (1854), de uma coleta realizada na Guiana Francesa. Posteriormente Petch (1948) quando revisou as espécies de Marasmius do Sri Lanka identificou uma espécie já descrita, Cantharellus elegans Berk. \& Broome como M. congregatus, sinonimizando essas espécies. Wannathes et al. (2004) revisaram todos os materiais associados à espécie M. pellucidus Berk. $\&$ Broome, incluindo $M$. congregatus e chegaram à conclusão de que o material identificado por Petch (1948) na verdade tratava-se de $M$. pellucidus e sinonimizaram Cantharellus elegans e M. congregatus sensu Petch. M. congregatus sensu Montagne passou a ser a única coleta da espécie. Na revisão de Wannathes et al. (2004), a descrição da espécie concorda em muitas características com a espécie encontrada no PEFI, porém os autores mencionam a ausência de caulocistídios. D.E. Desjardin (comunicação pessoal) esclareceu que no material revisado a base do estipe estava danificada o que não poderia confirmar realmente a ausência de caulocistídios e que o material encontrado no PEFI poderia ser um exemplar de $M$. congregatus. Desta forma esta é a segunda coleta da espécie já registrada e, portanto, a primeira citação para o Brasil.

Marasmius aff. pseudoniveus Singer, Sydowia 18: 340. 1965.

Figura 3 a-e

Píleo convexo-campanulado, creme-amarelado (palha), sulcado-reticulado na superfície, glabro, higrófano, margem irregular, 30-45 mm diâm. Lamelas adnatas, não colariadas, concolores ao píleo, próximas. Estipe central, cilíndrico, castanho-avermelhado, clareando e tornando-se concolor ao píleo da porção mediana até o ápice, levemente pubescente, oco, $60-75 \times 2-3 \mathrm{~mm}$. Basidiósporos oblongo-fusiformes, hialinos, lisos, inamilóides, parede fina, 6,2-7,7 × 2,5$3,7 \mu \mathrm{m}(\mathrm{Qm}=1,9 ; \mathrm{n}=20)$. Basídios não observados. Pleurocistídios ausentes. Queilocistídios semelhantes às estruturas da superfície pilear com células globosopiriformes lisas e células do tipo Siccus, hialinos,
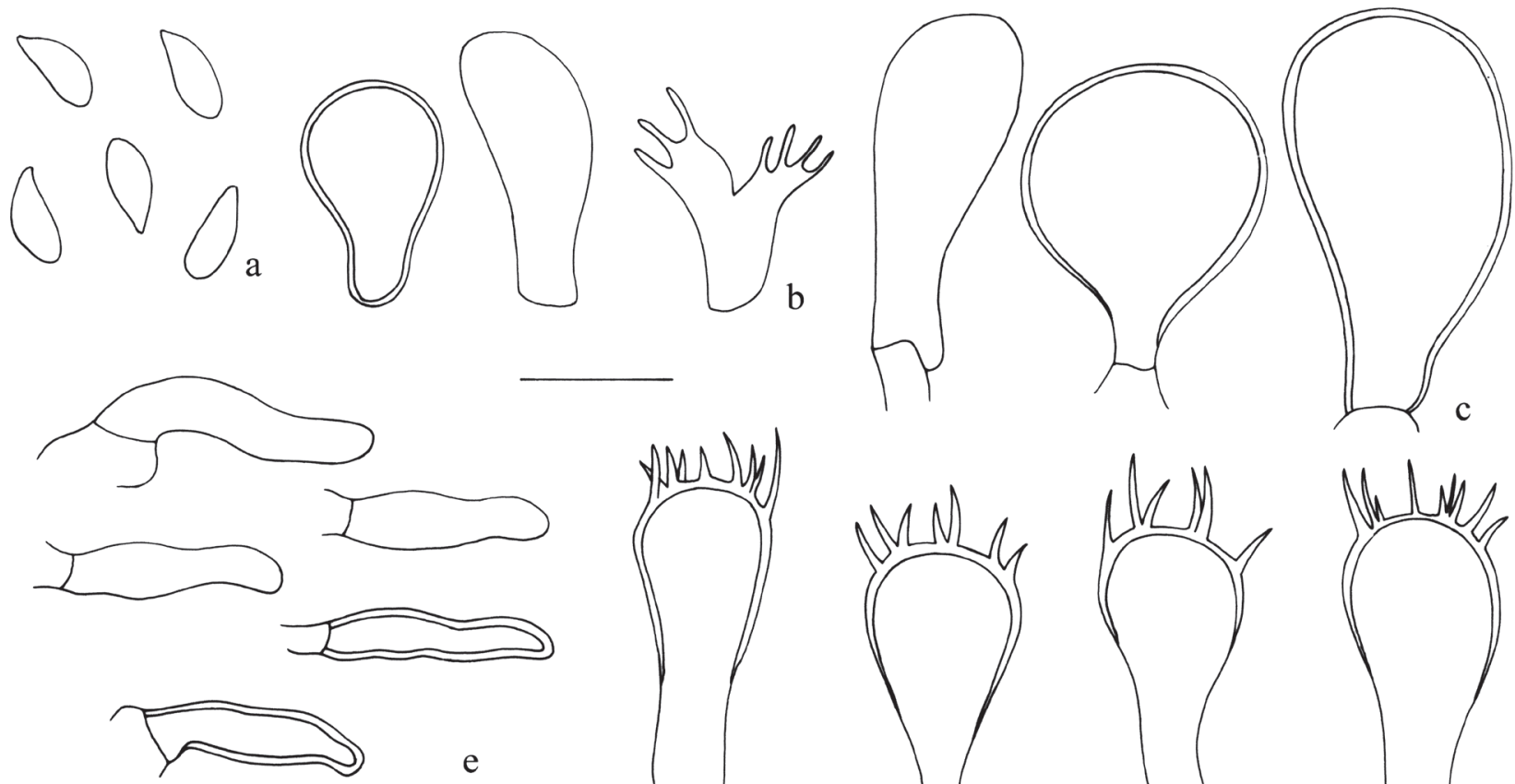

e
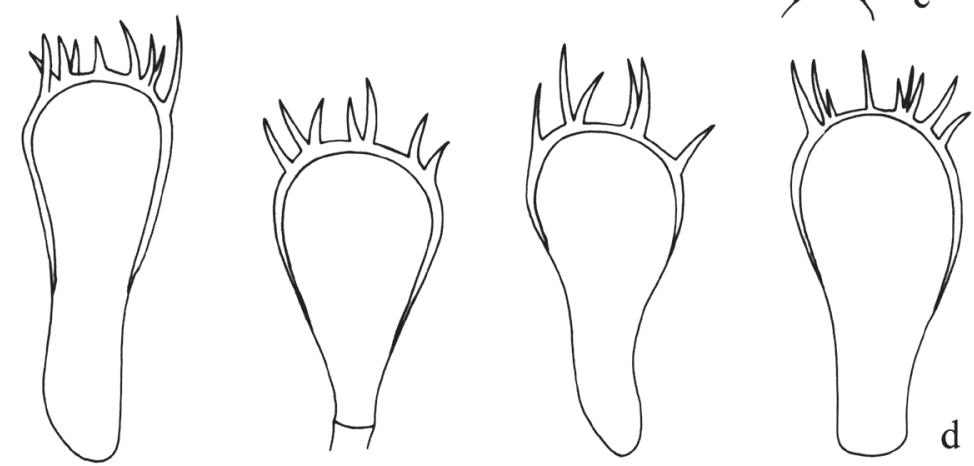

Figura 3. Marasmius aff pseudoniveus. a. Basidiósporos. b. Queilocistídios. c. Superfície pilear do tipo Globulares. d. Superfície pilear do tipo Siccus. e. Caulocistídios. Barra $=10 \mu \mathrm{m}$.

Figure 3. Marasmius aff.pseudoniveus. a. Basidiospores. b. Cheilocystidia.c. Pileipellis of Globulares type. d. Pileipellis of Siccus type. e. Caulocystidia. Bar $=10 \mu \mathrm{m}$. 
com parede fina, às vezes espessa. Trama da lamela regular, fortemente dextrinóide, com hifas hialinas, parede fina, septadas, com ansas, 3,7-6,2 um diâm. Superfície pilear formada por dois tipos de estruturas: a) do tipo Globulares, piriformes, hialinas, parede espessa, algumas com parede fina, 23-33 × 10-24 $\mu \mathrm{m}$; b) equinídios do tipo Siccus, piriformes, hialinos, parede espessa, 20-29 × 6,2-11,2 $\mu \mathrm{m}$ e sétulas apicais 2,5-7,5 um compr. Caulocistídios escassos, cilíndricoversiformes, 16,2-20 × 3,7-5 $\mu \mathrm{m}$. Basidioma disperso a gregário na serapilheira.

Material examinado: BRASIL. São PAULO: São Paulo, Parque Estadual das Fontes do Ipiranga, 8-II-2006 C. Puccinelli 177 (SP).

Material adicional examinado: BRASIL. São PAULO: Mogi-Guaçu, Fazenda Campininha, 29-30-I-1987, D.N. Pegler et al. s.n. (SP214424).

No material coletado no PEFI a coloração observada foi creme-amarelada e na descrição original a coloração do píleo é hialina tornando-se branca ou canela-clara até ocre conforme a secagem e quando bem seco, laranja na região marginal, com centro branco ou amarelo-ocráceo. As lamelas são adnatas e próximas, mas no material do PEFI são concolores com o píleo e na descrição original brancas. $\mathrm{O}$ estipe possui as mesmas características da descrição original, levemente pubescente, de coloração castanha clareando gradativamente até o ápice. Os basidiósporos são menores que os descritos por Singer (1965) de 8-10,3 × 2,7-4 $\mu \mathrm{m}$. Os pleurocistídios são ausentes e os queilocistídios semelhantes aos equinídios da superfície pilear que é composta por equinídios do tipo Siccus e também de células lisas do tipo Globulares. Os caulocistídios observados no material do PEFI são diferentes dos descritos por Singer (1965), pois são semelhantes à setas e no material do PEFI são cilíndrico-versiformes. A exsicata depositada no herbário (SP214421) de uma coleta realizada em Mogi-Guaçu (SP) e determinada por D.N. Pegler como M. pseudoniveus possui o mesmo tipo de caulocistídio observado no material coletado no PEFI.

A distribuição geográfica de $M$. pseudoniveus abrange a Bolívia (Singer 1976), Colômbia (Singer 1965, 1976) e Costa Rica (Ovrebo 1996). No Brasil é conhecida apenas no estado de São Paulo (Pegler 1997).

Chave de identificação para as espécies da série Haematocephali Singer do PEFI

1. Píleo rosado, rosa-escuro a vináceo

M. haematocephalus

1. Píleo de coloração alaranjada ou amarronzada

2. Basidiósporos pequenos, até $12,5 \mu \mathrm{m}$ de comprimento M. dennisii

2. Basidiósporos longos, maiores que $15 \mu \mathrm{m}$ de comprimento

3. Lamelas livres M.ferrugineus

3. Lamelas adnexas

4. Margem concolor ao píleo M. hypophaeus

4. Margem discolor ao píleo M. musicola

Marasmius dennisii Singer, Sydowia 18: 335. 1965.

Figura 4 a-d

Píleo convexo-campanulado a aplanado quando maduro, com uma pequena papila central, laranjaamarronzado com centro mais escuro, superfície glabra, margem lisa, 5-15 mm diâm. Lamelas livres, porém próximas do estipe, não colariadas, creme-amareladas, próximas; margem concolor, com lamélulas. Estipe central, cilíndrico, castanhoavermelhado, clareando no ápice, onde é concolor com as lamelas, glabro, oco, com micélio basal creme, 25-32 × $1 \mathrm{~mm}$. Basidiósporos fusiformeelipsóides, hialinos, lisos, inamilóides, parede fina, 10,5-12,5 × 3,7-5 um $(\mathrm{Qm}=2,7 ; \mathrm{n}=20)$. Basídios não observados. Pleurocistídios fusiformes, estrangulados no ápice, escassos, hialinos, parede fina, 31-36 × 5-6,2 $\mu \mathrm{m}$. Queilocistídios semelhantes aos equinídios da superfície pilear, hialinos, parede fina, 11,2-18,7 $\times$ 3,7-6,2 $\mu \mathrm{m}$. Trama da lamela regular, dextrinóide, com hifas hialinas, parede fina, septadas, com ansas, 2,5-5 um diâm. Superfície pilear himeniforme, com equinídios do tipo Siccus, corpo principal clavado, amarelo-amarronzado, parede fina a levemente 


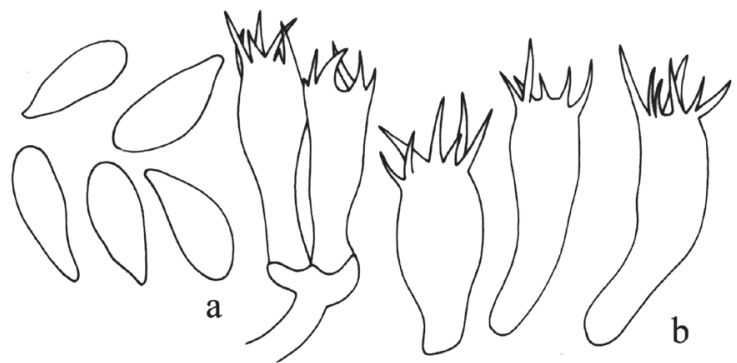

que também foi observado por Singer $(1965,1976)$. Esta espécie ocorre em Trinidad (Dennis 1951a, como M. leoninus, Singer 1965, 1976) e no Brasil, é mencionada para o estado de São Paulo (Grandi et al. 1984, Pegler 1997).

Marasmius ferrugineus (Berk.) Berk. \& M.A. Curt., Journ. Linn. Soc., Bot. 10: 297. $1869 \equiv$ Agaricus ferrugineus Berk., Lond. Journ. Bot. 2: 630, 1843.

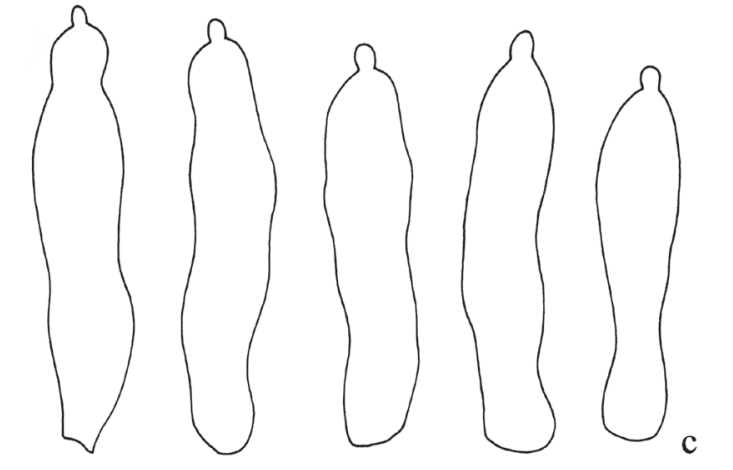

Figura 5 a-d

Píleo cônico quando jovem, tornando-se convexocampanulado, laranja-rosado a laranja-escuro, glabro, sulcado, margem crenada, 1-10 mm diâm. Lamelas livres, não colariadas, brancas a creme, distantes, 9-13 por basidioma, margem concolor ao píleo, sem lamélulas. Estipe central, filiforme, castanho-claro, clareando em direção ao ápice, onde é concolor com as lamelas, glabro, oco, micélio basal presente, quase imperceptível, 15-26 mm compr. Basidiósporos clavado-fusiformes, hialinos, lisos, inamilóides, parede fina, (13,7-)15-17,5 × 3,7(-5) $\mu \mathrm{m}(\mathrm{Qm}=1,8$; $\mathrm{n}=20$ ). Basídios clavados, tetraesporados, 24-31 $\times$ 7,5-8,7 $\mu \mathrm{m}$. Pleurocistídios mucronados, clavadoventricosos, estrangulados no ápice, hialinos, parede fina, 28-46 × 7,5-10 $\mu \mathrm{m}$. Queilocistídios semelhantes aos equinídios da superfície pilear, corpo principal hialino, parede fina a levemente espessada no ápice,

Figura 4. Marasmius dennisii. a. Basidiósporos. b. Pleurocistídios. c. Queilocistídios. d. Superfície pilear. Barra $=10 \mu \mathrm{m}$.

Figure 4. Marasmius dennisii. a. Basidiospores. b. Pleurocystidia. c. Cheilocystidia. d. Pileipellis. Bar $=10 \mu \mathrm{m}$.

espessada, 12,5-20 × 3,7-5 $\mu \mathrm{m}$, sétulas apicais 6,2$8,7 \mu \mathrm{m}$ compr.

Material examinado: BRASIL. São PAULO: São Paulo, Parque Estadual das Fontes do Ipiranga, 9-II-2006, $C$. Puccinelli 179 (SP).

Marasmius dennisii é caracterizado pelo píleo laranja-amarronzado e lamelas próximas com lamélulas de coloração creme-amarelada. Os basidiósporos descritos por Singer $(1965,1976)$ possuem dimensões que variam de 14-17 × 3-3,5 um e Pegler (1997) citou basidiósporos entre 12,5-17 $\times$ 3-4 um. Já os basidiósporos observados no material do PEFI variam de 10-12 × 3,7-5 $\mu$ m. Uma característica marcante da espécie são os pleurocistídios que não ultrapassam a linha himenial, mas são diferenciados pelo formato fusiforme levemente estrangulado, 11,2-16,2 × 3,7-7,5 $\mu \mathrm{m}$ e sétulas 5-6,2 $\mu \mathrm{m}$ compr. Trama da lamela regular, dextrinóide, com hifas hialinas, parede fina, septadas, com ansas, 2.5-6.2 $\mu \mathrm{m}$ diâm. Superfície pilear himeniforme com equinídios do tipo Siccus, corpo principal hialino a dourado, parede espessa, 11,2-17,5 × 3,7-6,2 $\mu \mathrm{m}$, sétulas 3,7$7,5 \mu \mathrm{m}$ compr. Basidioma disperso a gregário sobre ramos na serapilheira.

Material examinado: BRASIL. S̃̃o PAULO: São Paulo, Parque Estadual das Fontes do Ipiranga, 23-III-2005 C. Puccinelli 117 (SP); 23-III-2005, C. Puccinelli 120 (SP); 23-III-2005, C. Puccinelli 122 (SP); 7-IV-2005, C. Puccinelli 143 (SP).

Esta espécie é caracterizada pelo píleo cônicocampanulado de coloração laranja. Singer (1976) descreveu a coloração como ferruginosa, mas Desjardin et al. (2000) também descreveram uma coloração próxima do material encontrado no PEFI.As lamelas creme com margem concolor ao píleo e estipe com micélio basal escasso também são características marcantes. É muito semelhante à Marasmius hypophaeus distinguindo-se este por possuir o píleo 

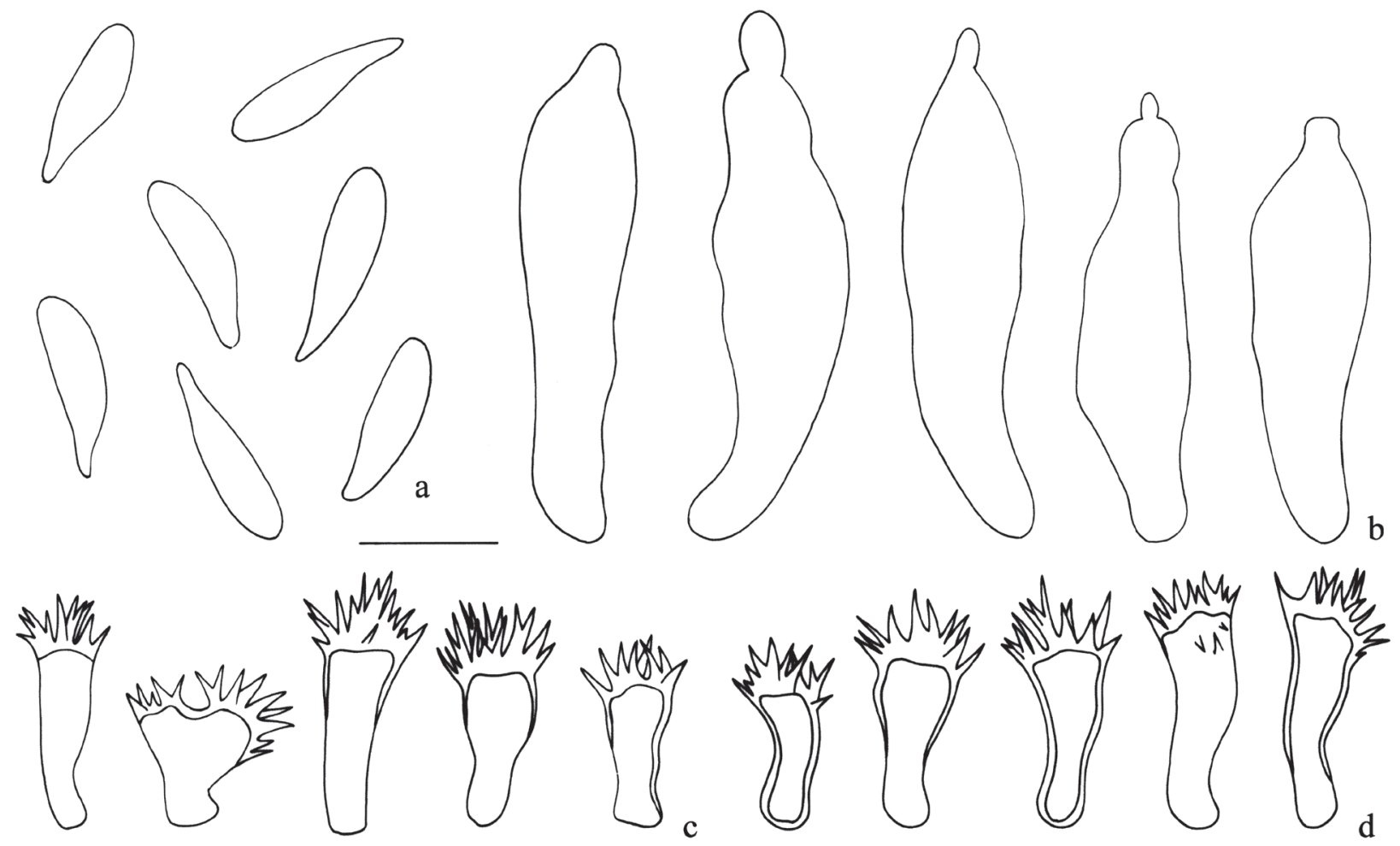

Figura 5. Marasmius ferrugineus. a. Basidiósporos. b. Pleurocistídios. c. Queilocistídios. d. Superfície pilear. Barra $=10 \mu \mathrm{m}$.

Figure 5. Marasmius ferrugineus. a. Basidiospores. b. Pleurocystidia. c. Cheilocystidia. d. Pileipellis. Bar $=10 \mu \mathrm{m}$.

de coloração mais forte e pelos pleurocistídios mais estrangulados. Singer (1965) citou esta espécie como M. gardneri Singer, sinonimizando-as posteriormente (Singer 1976). A distribuição geográfica abrange a Bolívia (Singer 1976), Indonésia (Desjardin et al. 2000), México (Silva \& Leon 1997), Porto Rico (Dennis 1951a, Singer 1965), Trinidad (Baker \& Dale 1951, Dennis 1951b) e Venezuela (Dennis 1961). No Brasil ocorre nos estados do Amazonas (Berkeley 1856, Berkeley \& Cooke 1876), Minas Gerais (Berkeley \& Cooke 1876, Singer 1965, 1976, Pegler 1988), Pernambuco (Kimbrough et al. 1994/1995), Rio de Janeiro (Singer 1965, 1976) e Rondônia (Capelari \& Maziero 1988). Esta é a primeira citação para o estado de São Paulo.

Marasmius haematocephalus (Mont.) Fr., Epicrisis: 382. $1838 \equiv$ Agaricus haematocephalus Mont., Ann. Sci. Nat., Bot. Ser. 2, 8: 396. 1837.

Figura 6 a-d

Píleo campanulado a convexo quando maduro, com uma pequena papila central em alguns espécimes, variando entre rosado, rosa-escuro ou vináceo, glabro, com aspecto velutino sob lupa, sulcado, membranáceo, margem crenada, 3-16 mm diâm. Lamelas livres a adnexas, não colariadas brancas a creme-rosadas, distantes, 6-7 por basidioma, margem concolor, às vezes com lamélulas. Estipe central, filiforme, castanho a castanho-escuro com o ápice creme, glabro, oco, micélio basal creme, 7-45 mm compr. Basidiósporos clavadofusiformes, hialinos, lisos, inamilóides, parede fina, 16,2-21 × 3,7-5 um ( $\mathrm{Qm}=4,6 ; \mathrm{n}=25$ basidiósporos $)$. Basídios clavados, tetraesporados. Pleurocistídios clavados, estrangulados e mucronados, hialinos, parede fina, alguns com a parede levemente espessa, 38-62 $\times$ 5-11,2 $\mu \mathrm{m}$. Queilocistídios semelhantes aos equinídios da superfície pilear, porém hialinos, 12,5-17,5 × 6,2-7,5 $\mu \mathrm{m}$. Trama da lamela regular, dextrinóide com hifas hialinas, septadas, com ansas, 3,7-7,5 um diâm. Superfície pilear himeniforme com equinídios do tipo Siccus, clavados, cilíndricos, amarronzados, parede espessa, alguns de parede fina na base, 8,7-18,7 ×3,7-7,5 $\mu \mathrm{m}$, sétulas apicais 3,7-6,2 $\mu \mathrm{m}$ compr. Basidioma disperso a gregário sobre folhas secas e gravetos na serapilheira. 


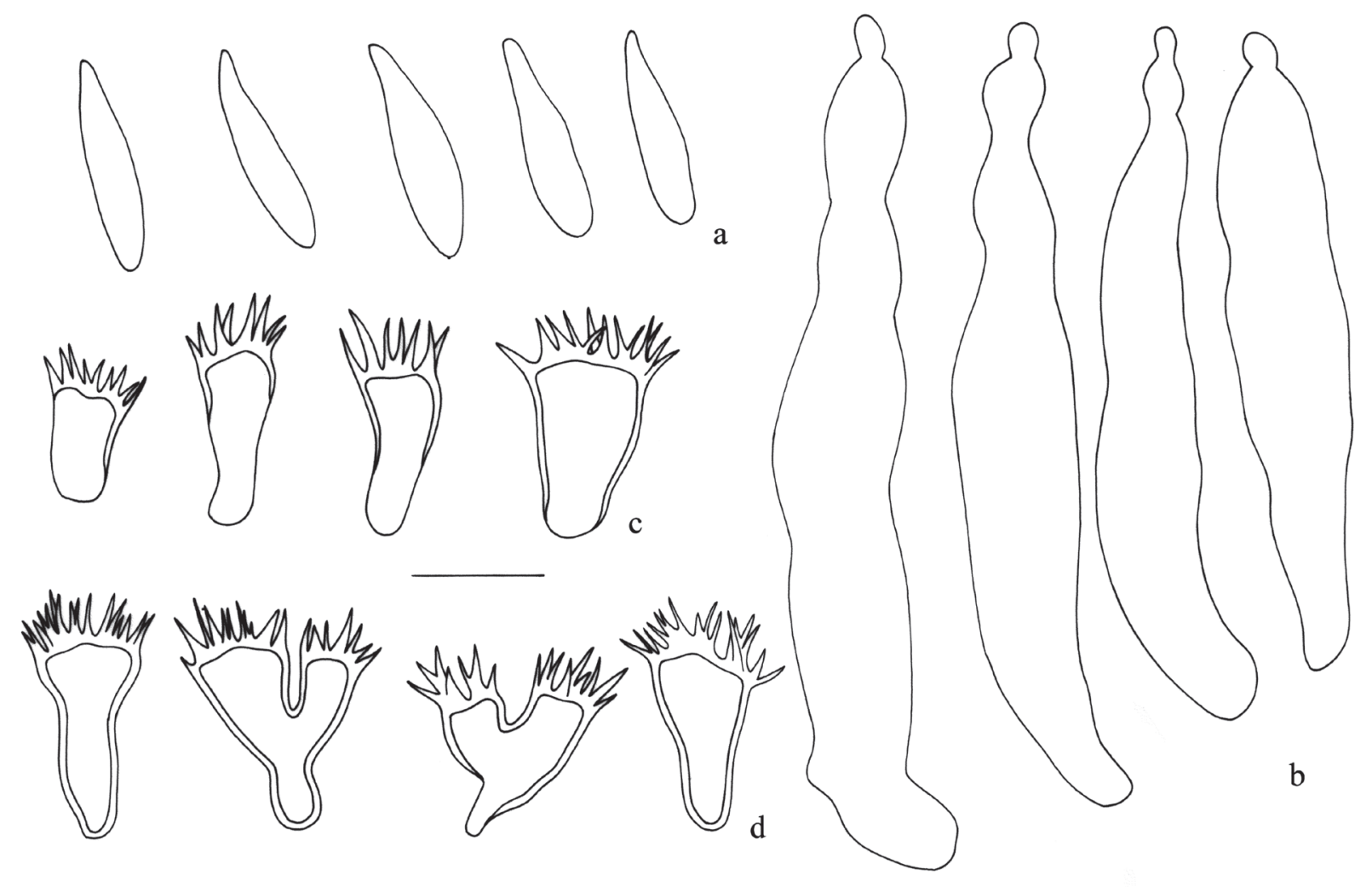

Figura 6. Marasmius haematocephalus. a. Basidiósporos. b. Pleurocistídios. c. Queilocistídios. d. Superfície pilear. Barra = $10 \mu \mathrm{m}$.

Figure 6. Marasmius haematocephalus. a. Basidiospores. b. Pleurocystidia. c. Cheilocystidia. d. Pileipellis. Bar $=10 \mu \mathrm{m}$.

Material examinado: BRASIL. SÃo PAULO: São Paulo, Parque Estadual das Fontes do Ipiranga, 1-I-1968, B. Skvortzov (SP103579); 20-I-1999, M. Capelari PEFI 2 (SP); 20-I-1999, M. Capelari PEFI 8 (SP); 13-XII-2001, M. Capelari 31/2001 (SP); 2-II-2004, C. Puccinelli 3(SP); 2-II-2004, C. Puccinelli 4 (SP); 2-II2004, C. Puccinelli 15 (SP); 16-II-2004, C. Puccinelli 36 (SP); 16-II-2004, C. Puccinelli 37 (SP); 16-II-2004, C. Puccinelli 38 (SP); 1-II-2005, C. Puccinelli 85 (SP); 1-II-2005, C. Puccinelli 88 (SP); 16-II-2005, C. Puccinelli 101 (SP); 16-II-2005, C. Puccinelli 102 (SP); 23-II-2005, C. Puccinelli 123 (SP); 1-IV-2005, C. Puccinelli 130 (SP); 1-IV-2005, C. Puccinelli 133 (SP); 1-IV-2005, C. Puccinelli 135 (SP); 7-IV-2005, C. Puccinelli 147 (SP).

Marasmius haematocephalus é facilmente reconhecido pela coloração do píleo que varia do rosado-claro ao vináceo, com lamelas distantes, brancas a creme-rosadas. Os pleurocistídios grandes e estrangulados e os basidiósporos também são características marcantes desta espécie. É uma espécie com ampla distribuição mundial e muito comum em florestas tropicais. No Brasil foi registrada para o Amazonas (Berkeley 1856, Berkeley \& Cooke 1876, Hennings 1904), Paraná (Meijer 2001), Pernambuco (Kimbrough et al. 1994/1995), Rio de Janeiro (Singer 1976), Rondônia (Capelari \& Maziero 1988) e São Paulo (Spegazzini 1889, Pegler 1997). Já foi mencionada para o PEFI por Bononi et al. (1981) como M. rhodocephalus.

Marasmius hypophaeus Berk. \& M.A. Curtis, Journ. Linn. Soc. Bot. 10: 298. 1869.

Figura 7 a-d

Píleo cônico quando jovem a campanulado com uma pequena papila central, marrom a vermelhoalaranjado, superfície rugosa, sulcado, membranáceo, margem crenada, 1-5 mm diâm. Lamelas adnexas, não colariadas, creme-alaranjadas, distantes, 14-16 por basidioma, sem lamélulas, margem concolor ao píleo. Estipe central, filiforme, castanho a castanhoescuro, tornando-se creme no ápice, glabro, oco, com micélio basal creme bem desenvolvido, 9-20 mm compr. Contexto fino, creme. Basidiósporos clavado- 


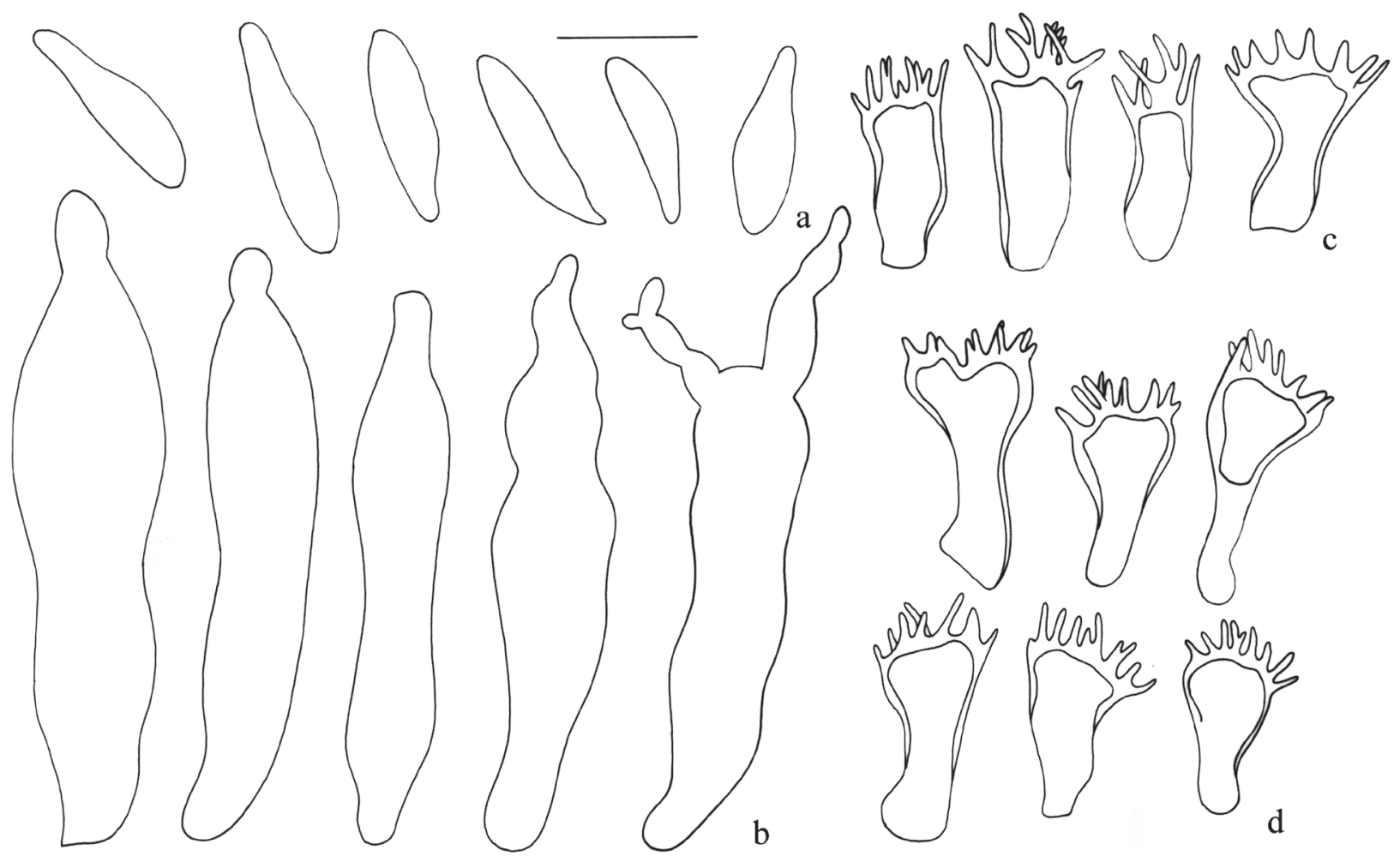

Figura 7. Marasmius hypophaeus. a. Basidiósporos. b. Pleurocistídios. c. Queilocistídios. d. Superfície pilear. Barra $=10 \mu \mathrm{m}$.

Figure 7. Marasmius hypophaeus. a. Basidiospores. b. Pleurocystidia. c. Cheilocystidia. d. Pileipellis. Bar $=10 \mu \mathrm{m}$.

fusiformes, hialinos, lisos, inamilóides, parede fina, 15-18,7 × 3,5-5 $\mu \mathrm{m}(\mathrm{Qm}=3,5 ; \mathrm{n}=30)$. Basídios clavados, tetraesporados. Pleurocistídios mucronados, fusóide-ventricosos, estrangulados, hialinos, parede fina, 36-60 × 6,2-10 $\mu \mathrm{m}$. Queilocistídios semelhantes aos equinídios da superfície pilear, corpo principal hialino, parede levemente espessada, 11,2-17,5 ×3,7$6,2 \mu \mathrm{m}$, sétulas apicais 3,7-6,2 $\mu \mathrm{m}$. Trama da lamela regular, dextrinóide, com hifas hialinas, parede fina, septadas, com ansas, 1,2-7,5 um diâm. Superfície pilear himeniforme com equinídios do tipo Siccus, corpo basal clavado, irregular, amarronzado, parede espessada principalmente na porção apical, 8,7-18,7 $\times 3,7-11,25 \mu \mathrm{m}$, sétulas apicais 3,7-5 $\mu \mathrm{m}$ compr. Basidioma gregário a disperso sobre folhas secas na serapilheira.

Material examinado: BRASIL. São PAULO: São Paulo, Parque Estadual das Fontes do Ipiranga, 16-I-1987, Pegler s.n. (SP214549); 16-II-2004, C. Puccinelli 25 (SP); 16-II-2004, C. Puccinelli 41 (SP); 1-IV-2005, C. Puccinelli 134 (SP).
Esta espécie é caracterizada pelo píleo marrom-alaranjado a vermelho-alaranjado e pelos pleurocistídios numerosos que podem variar de mucronados, fusóide-ventricosos e estrangulados, alguns com ramificações. A dimensão do píleo dos materiais encontrados no PEFI é menor que a mencionada por Singer $(1965,1976)$ de $7-17 \mathrm{~mm}$ de diâmetro, Pegler (1983) de 4-30 mm de diâmetro e por Desjardin et al. (2000) de 4-12 mm de diâmetro. Provavelmente a coleção do PEFI é constituída de basidiomas jovens, pois as demais características são coincidentes. Marasmius hypophaeus já foi encontrado em Cuba, Colômbia (Singer 1976), Dominica (Pegler 1983), Equador (Singer 1976), Indonésia (Desjardin et al.2000), Martinica (Pegler 1983) e México (Singer 1976) No Brasil, ocorre nos estados do Paraná (Meijer 2006) e São Paulo (Pegler 1997).

Marasmius musicola Murrill, N. Amer. Fl. 9: 260. 1915.

Figura 8 a-d 


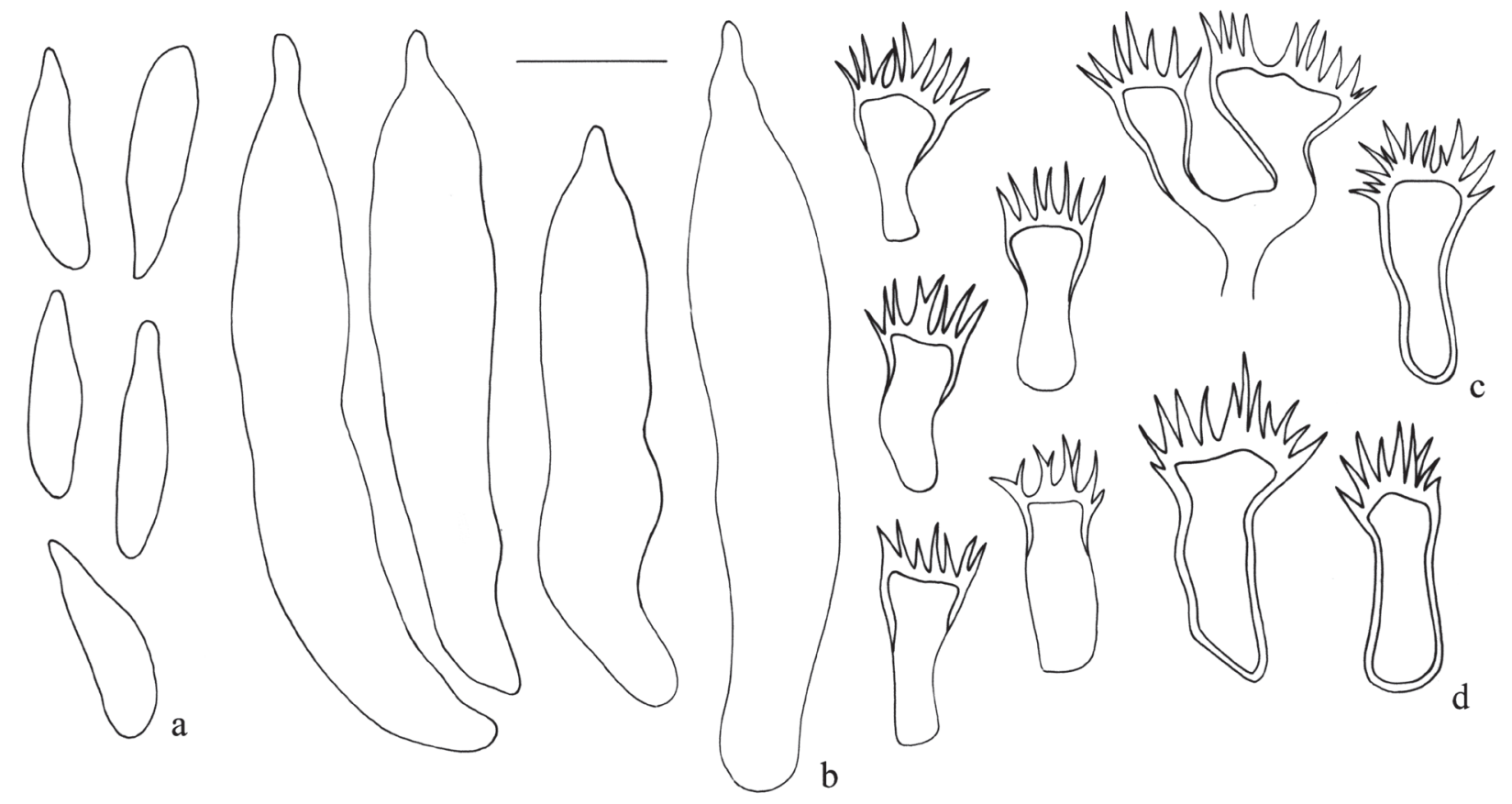

Figura 8. Marasmius musicola. a. Basidiósporos. b. Pleurocistídios. c. Queilocistídios. d. Superfície pilear. Barra $=10 \mu \mathrm{m}$.

Figure 8. Marasmius musicola . a. Basidiospores. b. Pleurocystidia. c. Cheilocystidia. d. Pileipellis. Bar $=10 \mu \mathrm{m}$.

Píleo cônico-campanulado, levemente umbonado, bege a marrom-claro com centro marrom-escuro, glabro, margem lisa, $15 \mathrm{~mm}$ diâm. Lamelas adnexas, creme, distantes, 14 por basidioma, margem concolor, sem lamélulas. Estipe central, filiforme, marromescuro tornando-se concolor com as lamelas no ápice, glabro, com micélio basal, $28 \mathrm{~mm}$ compr. Contexto fino, creme. Basidiósporos clavado-fusiformes, hialinos, lisos, inamilóides, parede fina, 15-23 $\times$ 3,7-5 $\mu \mathrm{m}(\mathrm{Qm}=4,4 ; \mathrm{n}=20)$. Basídios clavados, tetraesporados. Cistidíolos com conteúdo oleoso. Pleurocistídios mucronados, hialinos, parede fina, 40-65 × 7,5-11,2 um. Queilocistídios semelhantes aos equinídios da superfície pilear, corpo principal clavado, hialino, parede fina 12,5-16,2 × 3,7-8,7 $\mu \mathrm{m}$, sétulas apicais 7,5-8,7 $\mu \mathrm{m}$ compr. Trama da lamela regular, dextrinóide, com hifas hialinas, parede fina, septadas, com ansas, 3,7-5 um diâm. Superfície pilear himeniforme, com equinídios do tipo Siccus, corpo principal clavado, amarronzado, parede espessa 12,518,7 × 5-6,2 $\mu \mathrm{m}$, sétulas apicais 6,2-7,5 $\mu \mathrm{m}$ compr. Basidioma solitário sobre folha em decomposição na serapilheira.

Material examinado: BRASIL. São PAULO: São Paulo, Parque Estadual das Fontes do Ipiranga, 2-II-2004, $C$. Puccinelli 2 (SP).

Esta espécie é caracterizada pelo píleo bege a marrom-claro com centro umbonado marromescuro. É facilmente reconhecida pelos basidiósporos longos, pleurocistídios mucronados e cistidíolos com conteúdo oleoso. A distribuição geográfica da espécie abrange a Bolívia (Singer 1965), Cuba (Dennis 1951ab), Singer (1965, 1976), Estados Unidos da América (Singer 1965), Guadalupe (Pegler 1983) e México (Singer 1965). Esta é a primeira citação da espécie para o Brasil.

\section{Chave de identificação para as espécies da série Leonini Singer do PEFI}

1. Píleo laranja ou com tons alaranjados

2. Lamelas próximas

3. Basidiósporos 7,5-11,2 × 3-5 $\mu \mathrm{m}$ M.pseudosetosus 
3. Basidiósporos $10-13,7 \times 3,7-5 \mu \mathrm{m}$ M. aff. leoninus

2. Lamelas distantes

4. Basidioma solitário, píleo 19-21 mm de diâm. M. rhabarbarinus

4. Basidioma gregário a disperso, píleo 5-15 mm diâm.

5. Margem da lamela concolor ao píleo M. bambusiniformis

5. Margem da lamela discolor M. berteroi

1. Píleo sem tonalidade laranja ou alaranjada

6. Píleo com tonalidades marrons

7. Superfície pilear composta exclusivamente de equinídios M. bellus

7. Superfície pilear composta de equinídios e pileosetas

6. Píleo lilás M. dimorphus Marasmius sp.

Marasmius bambusiniformis Singer, Fl. Neotrop. Monogr. 17: 167. 1976.

Figura 9 a-d

Píleo convexo-campanulado, com uma pequena papila central, laranja a castanho-alaranjado, glabro, sulcado, margem crenada, 3-10 mm diâm. Lamelas adnexas, distantes, não colariadas, creme com margem concolor ao píleo, distantes, 10-15 por basidioma, sem lamélulas. Estipe central, filiforme, marrom com ápice concolor às lamelas, glabro, com micélio basal pouco desenvolvido, 20-50 mm compr. Basidiósporos cilíndrico-fusóides, lisos, hialinos, inamilóides, parede fina, 13,7-16,2 × 2,5-3,7 $\mu \mathrm{m}(\mathrm{Qm}=4,1$; $\mathrm{n}=20$ ). Basídios não observados. Basidíolos abundantes, fusóides a fusóide-mucronados, hialinos, parede fina, $15-25 \times 5-6,2 \mu \mathrm{m}$. Pleurocistídios ausentes. Queilocistídios semelhantes aos equinídios da superfície pilear, corpo principal cilíndrico-clavado, hialino, parede fina, 8,7-15 $\times$ 5-6.2 $\mu \mathrm{m}$. Trama da lamela regular, dextrinóide, com hifas hialinas, parede fina, septadas, com ansas, 2,5-3,7 um diâm. Superfície pilear himeniforme, com equinídios do tipo Siccus, corpo principal clavado, marrom-dourado, parede espessa, 8,7-18,7 ×3,7-7,5 $\mu \mathrm{m}$, sétulas apicais 3,7-6,2 $\mu \mathrm{m}$ compr. Basidioma disperso sobre folhas secas na serapilheira.

Material examinado: BRASIL. São PAulo: São Paulo, Parque Estadual das Fontes do Ipiranga, 2-II-2004, C. Puccinelli 1 (SP).

Marasmius bambusiniformis é caracterizado pelo píleo laranja a castanho-alaranjado, pelas lamelas distantes com a margem concolor ao píleo, estipe glabro com micélio basal escasso, basidiósporos fusóides e pela ausência de pleurocistídios, mas com numerosos basidíolos. Os basidiósporos encontrados no material
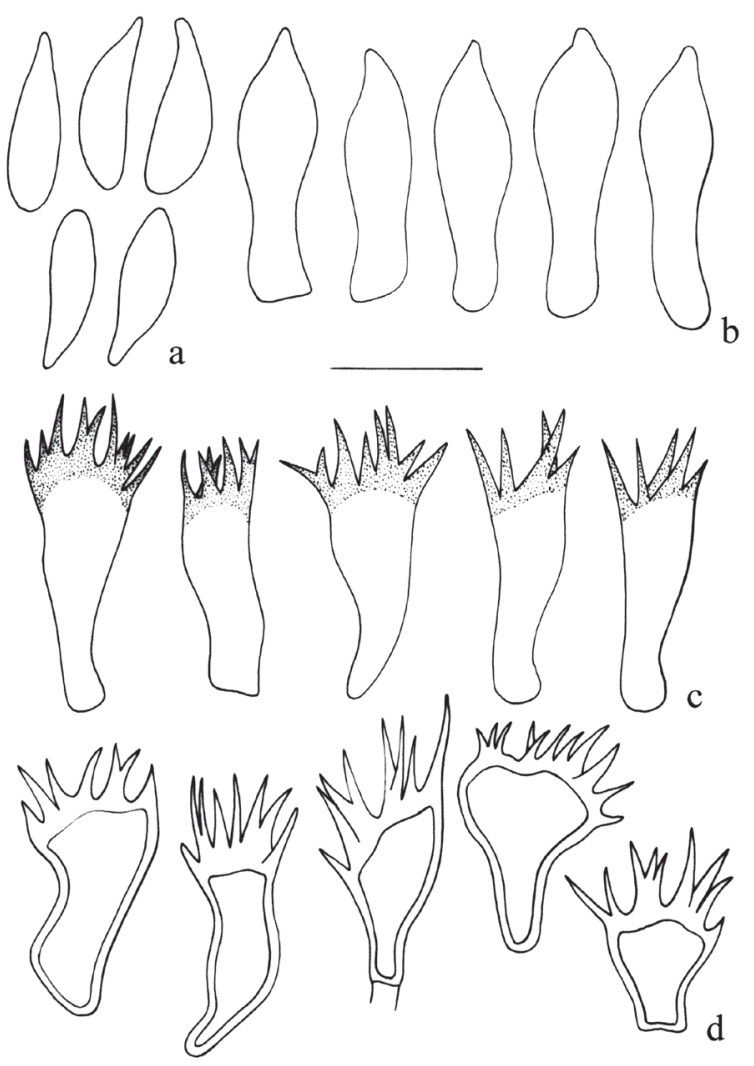

Figura 9. Marasmius bambusiniformis. a. Basidiósporos. b. Basidíolos. c. Queilocistídios. d. Superfície pilear. Barra $=10 \mu \mathrm{m}$.

Figure 9. Marasmius bamsufiniformis. a. Basidiospores. b. Basidioles. c. Cheilocystidia. d. Pileipellis. Bar $=10 \mu \mathrm{m}$.

do PEFI são menores do que os da descrição original de Singer (1976), que é de 15-18,5 × 3,7-5 $\mu \mathrm{m}$, porém concorda com as demais características. É muito semelhante macroscopicamente a $M$. ferrugineus, mas diferencia-se pela ausência dos pleurocistídios que estão presentes em M.ferrugineus. A distribuição 
geográfica abrange o Equador (Singer 1976, Desjardin \& Horak 1997), Estados Unidos da América e Papua Nova Guiné (Desjardin \& Horak 1997). No Brasil ocorre no estado de Pernambuco (Singer 1976). Esta é a primeira citação para o estado de São Paulo.

Marasmius bellus Berk., Hooker's Journ. Bot. 8: 139. 1856.

Figura 10 a-c

Píleo convexo a campanulado com um pequeno umbo, amarelo-amarronzado a castanho-claroamarelado com centro amarronzado, glabro, higrófano, levemente sulcado próximo à margem, margem lisa, 7-12 mm diâm. Lamelas adnexas, não colariadas, cremeamareladas com a margem concolor, subdistantes, com lamélulas. Estipe central, cilíndrico, castanho-escuroavermelhado, clareando no ápice até concolor com as lamelas, glabro, oco, micélio basal creme, bem desenvolvido, 10-20 × $1 \mathrm{~mm}$. Basidiósporos, oblongofusiformes, hialinos, lisos, inamilóides, parede fina, 10$13,7 \times 2,5-3,7(-5) \mu \mathrm{m}(\mathrm{Qm}=3,3 ; \mathrm{n}=25$ basidiósporos $)$. Basídios não observados. Pleurocistídios ausentes. Queilocistídios semelhantes aos equinídios da superfície pilear, corpo principal hialino, parede fina, 8,7-16,2 $\times$ 3,7-7,5 $\mu \mathrm{m}$, sétulas apicais hialinas, 3,7-7,5 $\mu \mathrm{m}$. Superfície pilear himeniforme com equinídios do tipo Siccus, corpo principal cilíndrico-clavado, dourado a

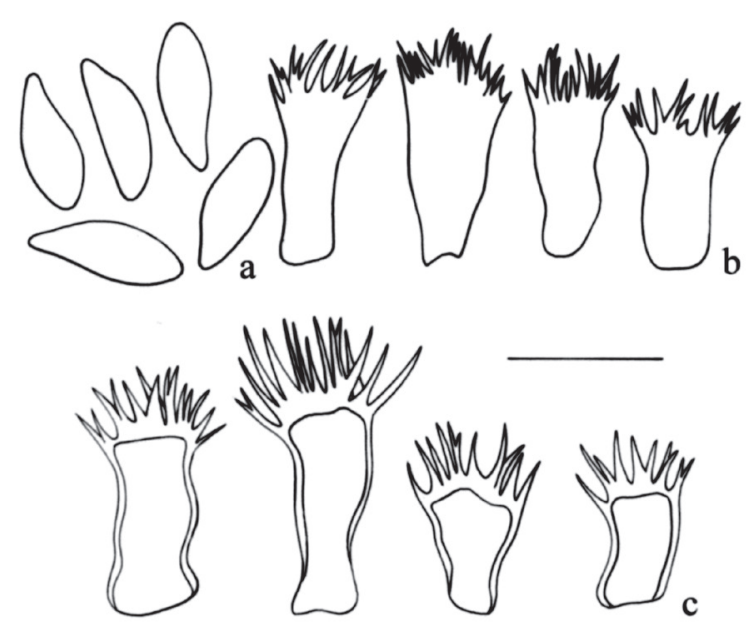

Figura 10. Marasmius bellus. a. Basidiósporos. b. Queilocistídios. c. Superfície pilear. Barra $=10 \mu \mathrm{m}$.

Figure 10. Marasmius bellus. a. Basidiospores. b. Cheilocystidia. c. Pileipellis. Bar $=10 \mu \mathrm{m}$. hialino, parede levemente espessada, principalmente próximo das sétulas apicais, 8,7-16,2 × 5-7,5 $\mu \mathrm{m}$, sétulas apicais hialinas, 3,7-7,5 $\mu \mathrm{m}$ compr. Trama da lamela regular, com hifas hialinas, dextrinóides, parede fina a levemente espessada, septadas, com poucas ansas, 2,5-7,5 um diâm. Basidioma disperso sobre madeira também encontrado sobre folhas de palmeira caídas no solo.

Material examinado: BRASIL. São PAULO: São Paulo, Parque Estadual das Fontes do Ipiranga, 16-II-2004. C. Puccinelli 24 (SP); 7-IV-2005, C. Puccinelli 146 (SP).

Marasmius bellus é caracterizado pelo tom amarelado do píleo, lamelas adnexas subdistantes com lamélulas e estipe castanho-escuro-avermelhado com micélio basal bem desenvolvido e basidiósporos oblongo-fusiformes. A medida dos basidiósporos segundo Singer $(1965,1976)$ é de 8-12,7 × 3-4,8 $\mu \mathrm{m}$; já Pegler (1983) cita 11-14 × 3,5-4,5 um, semelhante à variação do material coletado no PEFI. Pegler (1983) ainda cita a presença de basidíolos fusóides, uma característica que não foi observada no material analisado. M. bellus é próximo de $M$. leoninus diferindo na coloração do píleo e na dimensão dos basidiósporos. A distribuição geográfica da espécie abrange a Bolívia (Singer 1965, 1976, Pegler 1983), Costa Rica (Ovrebo 1996), Dominica, Martinica, Trinidad (Pegler 1983) e Venezuela (Dennis 1961). No Brasil ocorre nos estados do Amazonas (Berkeley 1856, Berkeley \& Cooke 1876, Dennis 1951c, Singer 1965, 1976, Pegler 1983, Pegler 1988, Souza \& Aguiar 2007), Pernambuco (Singer 1965, 1976) e São Paulo (Pegler 1997). É a primeira citação da espécie para o PEFI.

Marasmius berteroi (Lév.) Murrill, North American Flora 9: 267. 1915 $\equiv$ Heliomyces berteroi Lév. Ann. Sci. Nat. Bot. 2: 177. 1844.

Figura 11 a-c

Píleo cônico a campanulado quando maduro, umbonado, castanho-claro-alaranjado com centro mais escuro, glabro, sulcado, 5-15 mm diâm. Lamelas livres, não colariadas, creme, distantes a subdistantes, 15-18 por basidioma, com lamélulas presentes em alguns exemplares, margem concolor. Estipe central, filiforme, castanho-escuro clareando até creme-amarelado no ápice, glabro, oco, liso, com micélio basal creme, 25-36 mm compr. Basidiósporos fusóide-elipsóides, hialinos, lisos, inamilóides, parede fina, (10-)11,2-13,7 × 3,7-5 $\mu \mathrm{m}(\mathrm{Qm}=3,2 ; \mathrm{n}=25)$. 


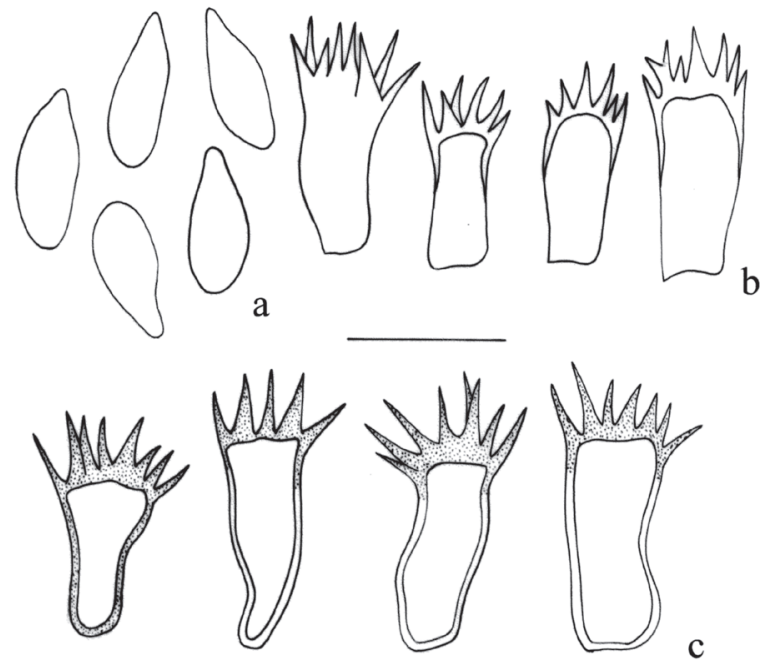

Figura 11. Marasmius cf. berteroi. a. Basidiósporos. b. Queilocistídios. c. Superfície pilear. Barra $=10 \mu \mathrm{m}$.

Figure 11. Marasmius cf. berteroi. a. Basidiospores. b. Cheilocystidia. d. Pileipellis. Bar $=10 \mu \mathrm{m}$.

Basídios hialinos, tetraesporados. Pleurocistídios ausentes. Queilocistídios semelhantes aos equinídios da superfície pilear, hialinos, parede levemente espessada, 8,7-12,5 × 5-7,5 um e sétulas 3,7-6,2 $\mu \mathrm{m}$ compr. Trama da lamela regular com hifas hialinas, dextrinóides, parede fina, septadas, com ansas, 5-8,7 um diâm. Superfície pilear himeniforme com equinídios do tipo Siccus, corpo principal clavado, amarelado a marrom-alaranjado, parede espessa, 10$23 \times 5-7,5 \mu \mathrm{m}$, sétulas 3,7-5 $\mu \mathrm{m}$ compr. Basidioma disperso a gregário sobre folhas secas.

Material examinado: BRASIL. São PAUlo: São Paulo, Parque Estadual das Fontes do Ipiranga, XI1961, Salles s.n.(SP60941); 10-XI-1982, G. Guzmán (SP177831); 24-I-1987, Pegler s.n.(SP214482); 2-II2004, C. Puccinelli 19 (SP); 2-II-2004, C. Puccinelli 20 (SP); 16-II-2004, C. Puccinelli 33 (SP).

Marasmius berteroi é uma espécie de ampla distribuição nos trópicos, sendo caracterizado pela coloração castanho-claro-alaranjada do píleo e do estipe, que quando jovem é amarelo tornando-se castanho quando maduro. Singer (1976) considera duas variedades, que diferem pelo tamanho e hábito do basidioma. Em M. berteroi var. berteroi, a dimensão do píleo é próxima da observada no material do PEFI e em $M$. berteroi var. major Singer, o tamanho do píleo varia de 10 a $56 \mathrm{~mm}$ de diâmetro, podendo ser confundido com $M$. rhabarbarinus, mas diferencia-se pela dimensão dos basidiósporos. A distribuição geográfica da espécie é bem ampla, ocorrendo na Argentina (Singer 1965, 1976, Singer \& Digilio 1952), Bali (Desjardin et al. 2000), Belize (Singer 1976), Bolívia (Singer 1965, 1976), Colômbia (Singer 1976), Costa Rica (Ovrebo 1996), Equador (Singer 1976), Honduras (Singer 1965), Java (Desjardin et al. 2000), Peru, Porto Rico (Singer 1976) e Venezuela (Dennis 1961, Dennis 1970). No Brasil, ocorre nos estados do Rio Grande do Sul (Sobestiansky 2005), Santa Catarina (Singer 1965, 1976) e São Paulo (Grandi et al. 1984, Pegler 1997).

Marasmius dimorphus C. Puccin. \& Capelari, Mycotaxon 95: 298. 2006.

Figura em Puccinelli \& Capelari (2006)

Píleo campanulado a convexo, bege a marromclaro ou marrom-rosado, com centro escuro quando fresco, tornando-se marrom-vináceo quando seco, superfície glabra, mas velutina sob lupa, membranáceo, sulcado, margem crenada, 12-20 mm diâm. Lamelas livres, creme, distantes, 17-18 por basidioma, lamélulas ausentes. Estipe central, filiforme, castanho, glabro, oco, com micélio basal creme, $48-56 \mathrm{~mm}$ compr. Contexto fino, branco-sujo, dextrinóide. Basidiósporos clavadofusiformes, lisos, hialinos, inamilóides, parede fina, 12,5-16,2 ×3,7-5 um $(\mathrm{Qm}=3,8 ; \mathrm{n}=25)$. Basídios não observados. Pleurocistídios ausentes. Queilocistídios semelhantes aos equinídios da superfície pilear, porém menores e de coloração mais clara, parede levemente espessa, 11,2-16,2 × 2,5-5 $\mu \mathrm{m}$. Trama da lamela regular, com hifas hialinas, dextrinóides, parede fina, septadas, com ansas, 1,2-3,7 $\mu \mathrm{m}$ diâm. Superfície pilear himeniforme, com equinídios do tipo Siccus e pileosetas; equinídios com corpo basal clavado, marrom-claro a dourado, parede espessa, 7,5-17,5 ×3,7-5 $\mu \mathrm{m}$; pileosetas com poucos ou muitos ramos, marrom-escuras, parede espessa, 33-45 × 5-6,2 $\mu \mathrm{m}$. Estipe com hifas corticais paralelas, hialinas a amarelo-amarronzadas, dextrinóides, parede espessa, 6,2-8,7 um diam. Caulocistídios ausentes. Basidioma solitário sobre graveto na serapilheira.

Material examinado: BRASIL, São PAULo, São Paulo, Parque Estadual das Fontes do Ipiranga, 10-X-2002, M. Capelari 4188 (SP), 19-XI-2002, M. Capelari 4205 (SP), 19-I-2005, C. Puccinelli 62 (SP), 7-IV-2005, C. Puccinelli 142 (SP). 
Marasmius dimorphus é caracterizado pela coloração do píleo, que varia de bege a marrom-clara, ou marrom-rosada, com centro mais escuro quando fresco e marrom-vinácea quando seco e pelas lamelas creme e distantes. As estruturas aqui chamadas de pileosetas possuem um formato distinto, com poucas ou muitas ramificações na porção apical, maiores e mais abundantes, próximo ao centro e menores e menos abundantes próximo à margem. Estas estruturas podem ser consideradas como intermediárias entre equinídios e setas verdadeiras e são diferenciadas pela coloração, espessura da parede e ausência de delimitação entre o corpo basal e as sétulas. Conhecida apenas para o estado de São Paulo (Puccinelli \& Capelari 2006).

Marasmius aff. leoninus Berk., Hooker's. Jour. Bot. 8: 135.1856.

Figura 12 a-c

Píleo convexo a aplanado quando maduro, amarelo-alaranjado a laranja, glabro, higrófano, ligeiramente sulcado na borda, margem crenulada, 13-35 mm diâm. Lamelas adnexas, não coloriadas, brancas a creme, subdistantes a próximas, margem concolor, com lamélulas. Estipe central, cilíndrico, marrom-avermelhado com ápice creme, glabro, oco,
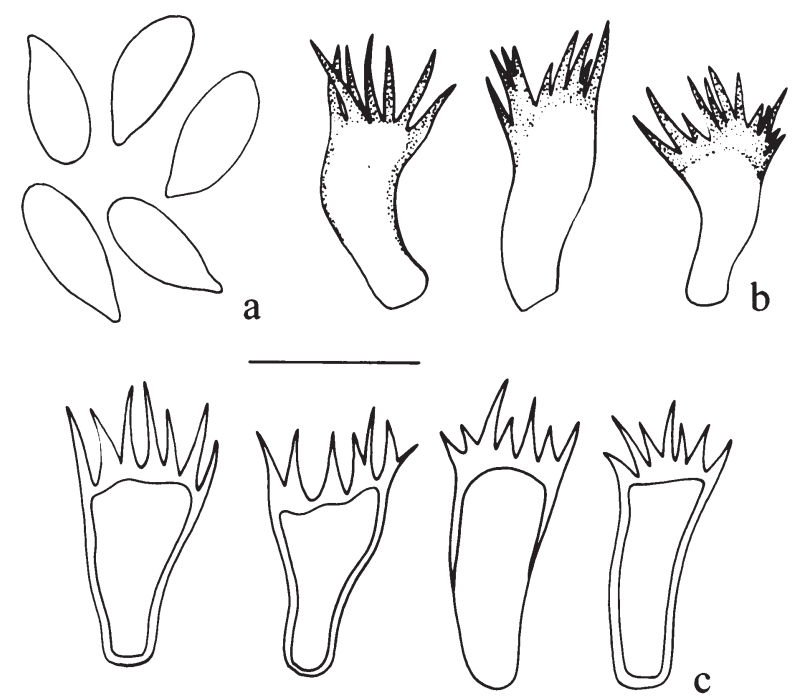

Figura 12. Marasmius ef. leoninus. a. Basidiósporos. b. Queilocistídios. c. Superfície pilear. Barra $=10 \mu \mathrm{m}$.

Figure 12. Marasmius cf. leoninus. a. Basidiospores.b. Cheilocystidia. c. Pileipellis. Bar $=10 \mu \mathrm{m}$. micélio basal bem desenvolvido, 37-50 × $1 \mathrm{~mm}$. Basidiósporos oblongo-fusóides, hialinos, lisos, inamilóides, parede fina, $(8,7)$ 10-12,5 (13,7) × 3,7 (5) $\mu \mathrm{m}(\mathrm{Qm}=2,9 ; \mathrm{n}=20)$. Basídios tetraesporados. Basidíolos mucronados, hialinos, parede fina. Pleurocistídios ausentes. Queilocistídios semelhantes aos equinídios da superfície pilear, corpo principal cilíndrico-clavado, hialino, parede fina, 7,5-15 × 3,7$6,2 \mu \mathrm{m}$, sétulas apicais levemente douradas, 5-7,5 $\mu \mathrm{m}$ compr. Trama da lamela regular, com hifas hialinas, dextrinóides, parede fina, septadas, com ansas, 3,76,2 um diâm. Superfície pilear himeniforme, com equinídios do tipo Siccus, corpo principal cilíndricoclavado, marrom-dourado, parede espessa, 8,7-15 $\times$ 5-6,2 $\mu \mathrm{m}$, sétulas apicais 6,2-7,5 $\mu \mathrm{m}$ compr. Basidioma disperso sobre folhas e gravetos na serapilheira.

Material examinado: BRASIL. São PAUlo. São Paulo, Parque Estadual das Fontes do Ipiranga, 16-II-2004, C. Puccinelli 27 (SP); 16-II-2004, C. Puccinelli 28 (SP); 16-II-2004, C. Puccinelli 32 (SP).

Esta espécie é caracterizada pelo píleo amareloalaranjado a laranja com lamelas adnexas próximas e estipe marrom-avermelhado. Segundo Pegler (1983), as lamelas são espaçadas, o que não ocorre no material coletado no PEFI, mas Pegler (1983) comenta também que o espaçamento entre as lamelas é um caráter variável para esta espécie. Singer (1965, 1976) cita lamelas próximas a distantes o que pode confirmar a variação deste caráter. É uma espécie de difícil determinação, pois apresenta características variáveis, como a presença de pruinosidade no estipe, que não foi observada no material do PEFI; hifas da trama do píleo e lamelas de parede fina a espessa em alguns exemplares e a presença ou ausência de queilocistídios. Esta espécie é comum desde o sul da Florida (Estados Unidos da América) até o nordeste da Argentina (Singer 1965, 1976), incluindo também, Bolívia (Singer 1976), Costa Rica (Ovrebo 1996), Equador (Singer 1976), Venezuela (Dennis 1951ac, Singer 1976). No Brasil é encontrada nos estados do Amazonas (Berkeley 1856, Berkeley \& Cooke 1876, Singer 1965, 1976, Souza \& Aguiar 2007), Paraná (Meijer 2006), Rio Grande do Sul (Singer 1965, 1976), Rondônia (Capelari \& Maziero 1988) e São Paulo (Pegler 1997).

Marasmius pseudosetosus C. Puccin. \& Capelari, Mycotaxon 95: 295. 2006.

Figura em Puccinelli \& Capelari (2006) 
Píleo convexo a campanulado, aplanado quando maduro com uma pequena papila central, laranja-claro com centro laranja-escuro, centro reticulado, glabro, higrófano, margem lisa, 5-20 mm diâm.Lamelas livres, mas muito próximas ao estipe, pseudocolar presente nos espécimes jovens, branco-sujas a creme, próximas, margem concolor, com lamélulas. Estipe central, cilíndrico, marrom-avermelhado a vináceo, tornandose mais claro em direção ao ápice onde é concolor com as lamelas, glabro, oco, presença de um micélio basal bem desenvolvido creme-amarelado a creme, 30$42 \times 1 \mathrm{~mm}$. Contexto fino, dextrinóide. Basidiósporos fusóide-elipsóides, hialinos, lisos, inamilóides, parede fina, 7,5-11,2 × 3-5um $(\mathrm{Qm}=2,5 ; \mathrm{n}=40)$. Basídios não observados. Pleurocistídios ausentes. Queilocistídios de dois tipos: a) similares aos equinídios da superfície pilear, hialinos e raramente encontrados; b) estruturas clavadopiriformes, lisas, hialinas, parede fina a espessa, 17,5-21 $\times$ 7,5-8,7 $\mu \mathrm{m}$. Trama da lamela regular, dextrinóide, com hifas, hialinas, parede fina, septadas, com ansas, 2,5-5 um diâm. Superfície pilear himeniforme, com equinídios do tipo Siccus, e estruturas de transição entre equinídios e pileosetas. Equinídios do tipo Siccus com corpo principal clavado, hialino, alguns marrons ou dourados, parede espessa, 13,7-20 × 3,77,5 $\mu \mathrm{m}$, sétulas apicais 6,2-8,7 $\mu \mathrm{m}$ compr.; estruturas de transição escassas, amarronzadas, parede espessa, algumas com formato semelhante aos equinídios, $31-55 \times 5-8,7 \mu \mathrm{m}$. Basidioma disperso sobre folhas secas na serapilheira.

Material examinado: BRASIL: São PAULo. São Paulo, Parque Estadual das Fontes do Ipiranga, 19-X-2002, M. Capelari 4191 (SP); 19-X-2002, M. Capelari 4196 (SP); 30-III-2005, C. Puccinelli 125 (SP); 30-III-2005, C. Puccinelli 126 (SP); 1-IV-2005, C. Puccinelli 131 (SP); 1-IV-2005, C. Puccinelli 132 (SP).

Esta espécie é caracterizada pelo píleo higrófano, laranja-claro, reticulado no centro onde é laranja mais escuro, lamelas próximas com lamélulas e pela coloração do estipe. Microscopicamente pelos basidiósporos elipsóide-fusóides, pequenos, ausência de pleurocistídios, presença de queilocistídios dimórficos e pela presença de estruturas setiformes entre os equinídios da superfície pilear (melhor visualizadas quando o material é esmagado na lâmina). A maioria destas estruturas setiformes possui o mesmo formato dos equinídios, mas distingue-se por terem dimensão maior, pela espessura da parede e coloração mais escura. Estas estruturas podem ser consideradas intermediárias entre setas e equinídios. Dentre as outras espécies de Marasmius com setas na superfície pilear, M. pseudosetosus difere pela coloração do píleo e estipe e pelos queilocistídios dimórficos. Esta espécie é bem comum no PEFI.

Marasmius rhabarbarinus Berk., Hooker's. Jour. Bot. 8: 135. 1856.

Figura 13 a-c

Píleo convexo, margem crenada, laranja-escuro a laranja-ferruginoso com centro ferrugem, glabro, membranáceo, sulcado, 19-21 mm diâm. Lamelas livres, não colariadas, creme a creme-alaranjadas, subdistantes a distantes, 13-15 por basidioma, margem concolor ao píleo, mas algumas concolores com as lamelas, lamélulas em duas séries. Estipe central, cilíndrico, castanho a castanho-escuro com o ápice tornando-se alaranjado, glabro, oco, com micélio basal creme, 75-80 × 1-2 mm. Basidiósporos

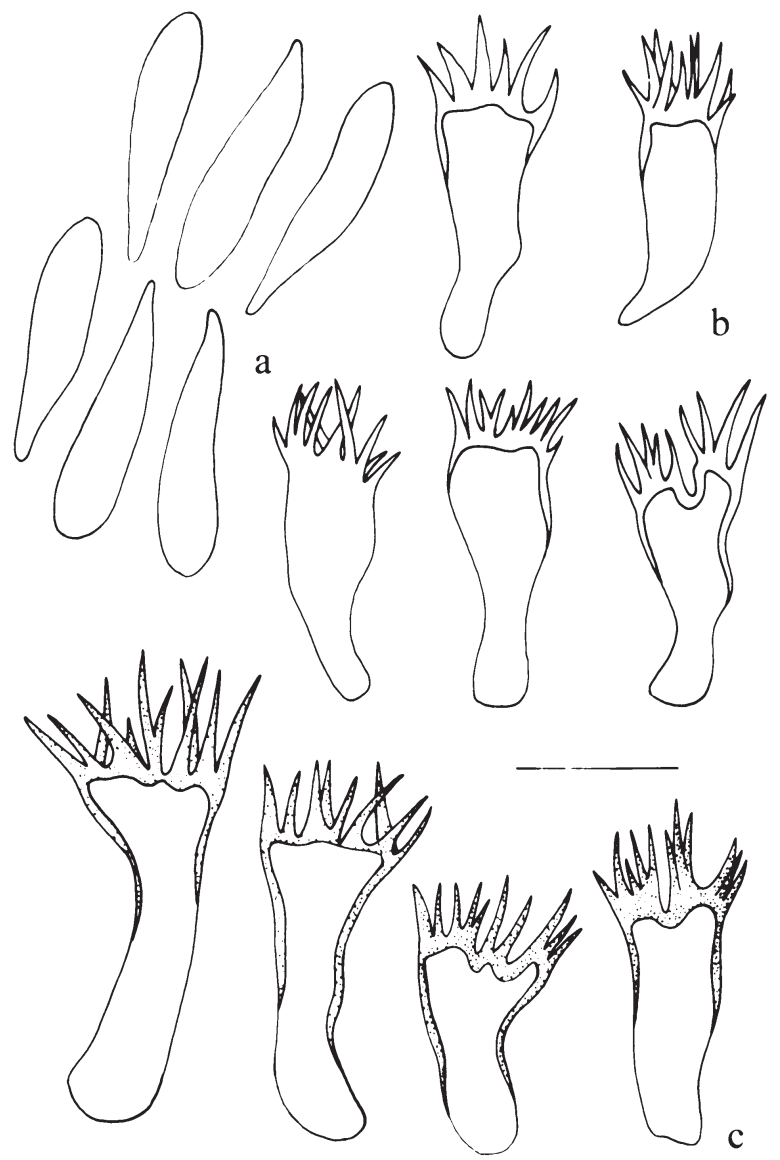

Figura 13. Marasmius rhabarbarinus. a. Basidiósporos. b. Queilocistídios. c. Superfície pilear. Barra $=10 \mu \mathrm{m}$. Bar $=10 \mu \mathrm{m}$.

Figure 13. Marasmius rhabarbarinus. a. Basidiospores. b. Cheilocystidia. c. Pileipellis. 
clavado-fusiformes a cilíndricos, hialinos, lisos, inamilóides, parede fina, 17,5-22,5 × 3,7-5 $\mu \mathrm{m}(\mathrm{Qm}$ $=4 ; \mathrm{n}=20$ basidiósporos). Basídios não observados. Pleurocistídios ausentes. Queilocistídios semelhantes aos equinídios da superfície pilear, recobrindo toda a borda da lamela, hialinos, parede fina a levemente espessada no ápice, 15-23,7 × 3,7-6,2 $\mu \mathrm{m}$, sétulas $3,7-8,7 \mu \mathrm{m}$ compr. Trama da lamela irregular, com hifas hialinas, dextrinóides, parede fina a levemente espessada, septadas, com poucas ansas, 2,5-8,5 $\mu \mathrm{m}$ diâm. Superfície pilear himeniforme, com equinídios do tipo Siccus, corpo principal cilíndrico-clavado, alguns sem delimitação entre o corpo principal e as sétulas, marrom-dourado, parede espessa, às vezes fina na região inferior, 11,2-27,5 × 2,5-6,2 $\mu \mathrm{m}$, sétulas 6,2-10 um compr. Basidioma solitário sobre folhas ou madeira na serapilheira.

Material examinado: BRASIL. SÃo PAULO: São Paulo, Parque Estadual das Fontes do Ipiranga, 19-I-2005, C. Puccinelli 168 (SP); 8-II-2005, C. Puccinelli 172 (SP); 20-X-2006, C. Puccinelli 195 (SP).

Esta espécie chama atenção pelo hábito solitário sobre folhas e madeira em decomposição na serapilheira; pelo píleo laranja com lamelas distantes, creme a creme-alaranjadas com lamélulas de dois tamanhos. Microscopicamente é caracterizada pelos basidiósporos clavado-fusiformes ligeiramente curvos na região basal e superfície pilear com alguns equinídios sem delimitação entre corpo principal e sétulas. A descrição dos basidiósporos é semelhante à de Singer $(1965,1976)$, mas as dimensões por ele fornecida de 14-21 × 2,3-3,8 $\mu \mathrm{m}$, são ligeiramente menores do que as observadas no material do PEFI. M. rhabarbarinus é muito próximo a $M$. mazateus Singer, descrita do México (Singer 1976), mas difere na dimensão do píleo que não excede $17 \mathrm{~mm}$ de diâmetro na última espécie e pelo número de lamelas. A distribuição geográfica de $M$. rhabarbarinus inclui Argentina (Singer 1965, 1976), Bolívia (Singer 1976) e Venezuela (Dennis 1951a, 1961). No Brasil, ocorre nos estados do Amazonas (Berkeley 1856, Berkeley \& Cooke 1876, Singer 1958, 1965, 1976, Pegler 1988) e São Paulo (Pegler 1997).

\section{Marasmius sp.}

Figura 14 a-c

Píleo convexo, com um pequeno umbo, lilás com centro vinho, glabro, sulcado, margem crenada, 12-17 mm diâm. Lamelas livres, creme-rosadas,

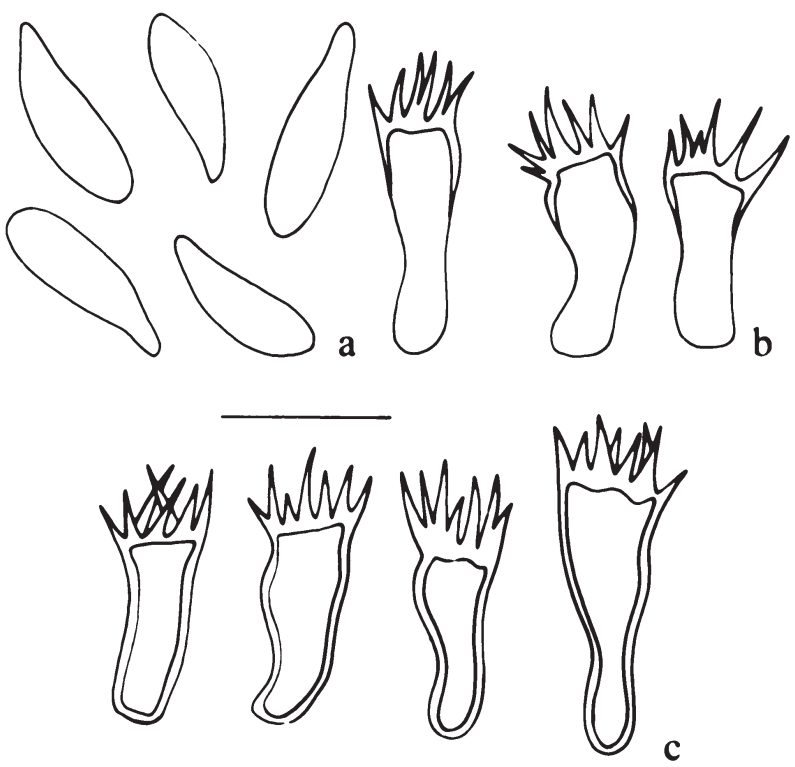

Figura 14. Marasmius cf. tageticolor. a. Basidiósporos. b. Queilocistídios. c. Superfície pilear. Barra $=10 \mu \mathrm{m}$.

Figure 14. Marasmius cf. tageticolor. a. Basidiospores. b. Cheilocystidia. d. Pileipellis. Bar $=10 \mu \mathrm{m}$.

distantes, 10-12 por basidioma, com a margem concolor, sem lamélulas. Estipe central, filiforme, castanho-escuro tornando-se creme no ápice, glabro, oco, micélio basal creme bem desenvolvido, 60-67 mm compr. Contexto fino, creme. Basidiósporos fusóide-clavados, hialinos, lisos, inamilóides, parede fina, 12,5-17,5 × 3,7-5,0 $(\mathrm{Qm}=3,6 ; \mathrm{n}=20)$. Basídios clavados, tetraesporados. Pleurocistídios ausentes. Queilocistídios semelhantes aos equinídios da superfície pilear, corpo principal cilíndrico-clavado, hialino, parede fina, espessada na porção superior, 13,7-16,2 × 3,7-5 $\mu \mathrm{m}$, sétulas apicais 3,7-5,2 $\mu \mathrm{m}$ compr. Trama da lamela dextrinóide, com hifas hialinas, parede fina, septadas, com ansas, 3,7-7,5 um diâm. Superfície pilear himeniforme, com equinídios do tipo Siccus, corpo principal cilíndrico-clavado, amarronzado, parede espessa, 13,7-17,5 × 3,7-5 $\mu \mathrm{m}$, sétulas apicais 3,7-6,5 $\mu \mathrm{m}$ compr. Basidioma disperso sobre gravetos e folhas secas na serapilheira.

Material examinado: BRASIL. São PAUlo: São Paulo, Parque Estadual das Fontes do Ipiranga, 16-II-2004. C. Puccinelli et al. 29 (SP).

Macroscopicamente, esta espécie é semelhante a $M$. haematocephalus, principalmente pelo hábito e coloração do píleo, porém difere pela ausência de 
pleurocistídios. Pode também ser confundido com Marasmius phaeus Berk. \& M.A. Curtis, que é distinto por ter as lamelas brancas com a margem marromavermelhada e sem coloração violácea no píleo.

O material analisado é próximo de Marasmius tageticolor Berk. sensu Desjardin et al. (2000), porém esta espécie tem muitas interpretações na literatura (Dennis 1951a, Pegler 1983, Desjardin et al. 2000), sendo as descrições de Singer $(1965,1976)$ as que mais condizem com a descrição original de Berkeley (1856). Será necessário coletar mais material desta espécie para que ela possa ser corretamente identificada.

\section{Agradecimentos}

As autoras agradecem à FAPESP (processo 04/04319-2) pelo apoio financeiro. A primeira autora agradece ao CNPq pela bolsa de mestrado concedida.

\section{Literatura citada}

Baker, R.E.D. \& Dale, W.T. 1951. Fungi of Trinidad and Tobago. Mycological Papers 33: 1-123.

Barbosa, L.M., Potomati, A. \& Peccinini, A.A. 2002. O PEFI: histórico e legislação. In: D.C. Bicudo, M.C, Forti \& C.E.M. Bicudo (orgs.). Parque Estadual das Fontes do Ipiranga (PEFI): unidade de conservação que resiste a urbanização de São Paulo, Secretaria do Meio Ambiente, São Paulo, pp. 15-28.

Berkeley, M.J. 1856. Decades of fungi LI-LIV.: Rio Negro Fungi. Hooker's, Journal of Botany \& Kew Miscellaneous 8: 129-144.

Berkeley, M.J. \& Cooke, M.C. 1876. The fungi of Brazil, including those collected by J. W. H. Trail. Journal of the Linnean Society 15: 363-398.

Bononi, V.L.R., Trufem, S.F.B. \& Grandi, R.A.P. 1981. Fungos macroscópicos do Parque Estadual das Fontes do Ipiranga, São Paulo, Brasil, depositados no Herbário do Instituto de Botânica. Rickia 9: 37-53.

Capelari, M.\& Maziero, R. 1988. Fungos macroscópicos do estado de Rondônia região dos rios Jaru e Ji-Paraná. Hoehnea 15: 28-36.

Dennis, R.W.G. 1951a. Some Agaricaceae of Trinidad and Venezuela. Leucosporae: Part 1. Transactions of the British Mycological Society 34: 411-480.

Dennis, R.W.G. 1951b. Murrill's West Indian species of Marasmius. Kew Bulletin 6: 196-210.

Dennis, R.W.G. 1951c. Species of Marasmius described by Berkeley from tropical America. Kew Bulletin 6: 153-163.

Dennis, R.W.G. 1961. Fungi Venezuelani: IV. Agaricales. Kew Bulletin 15: 67-156.
Dennis, R.W.G. 1970. Fungus flora of Venezuela and adjacent countries. Kew Bulletin Additional Series 3: $1-531$.

Desjardin, D.E. \& Horak, E. 1997. Marasmius and Gloiocephala in the South Pacific Region: Papua New Guinea, New Caledonia, and New Zealand taxa. Part 1. Papua New Guinea and New Caledonia taxa. Part 2. New Zealand taxa. Bibliotheca Mycologica 168: 1-152.

Desjardin, D.E. \& Ovrebo, C.L. 2006. New species and new records of Marasmius from Panamá. Fungal Diversity 21: 19-39.

Desjardin, D.E., Retnowati, A. \& Horak, E. 2000. Agaricales of Indonesia. 2. A preliminary monograph of Marasmius from Java and Bali. Sydowia 52: 92-194.

Fernandes, A.J., Reis, L.A.M. \& Carvalho, A. 2002. Caracterização do meio físico. In: D.C. Bicudo, M.C. Forti \& C.E.M. Bicudo (orgs.). Parque Estadual das Fontes do Ipiranga (PEFI): unidade de conservação que resiste a urbanização de São Paulo. Secretaria do Meio Ambiente, São Paulo, pp. 51-62.

Grandi, R.A.P., Guzmán, G. \& Bononi, V.L.R. 1984. Adições às Agaricales (Basidiomycetes) do Parque Estadual das Fontes do Ipiranga, São Paulo, SP, Brasil. Rickia 11: 27-33.

Hennings, P. 1904. Fungi amazonici I. a cl. Ernesto Ule collecti. Hedwigia 43: 154-186.

Kimbrough, J.W.,Alves, M.H. \& Maia,L.C. 1994/1995. Basidiomycetes saprófitos presentes em troncos vivos e em folhedo de "sombreiro" (Clitoria fairchildiana [Benth.] Howard). Biologica Brasilica 6: 51-56.

Meijer, A.A.R. 2001. Mycological work in the Brazilian state of Paraná. Nova Hedwigia 72: 105-159.

Meijer,A.A.R. 2006. Preliminary list of the macromycetes from the Brazilian State of Paraná. Boletim do Museu Botânico Municipal 68: 1-55.

Montagne, C. 1854. Cryptogamia guayanensis. Annales des Sciences Naturelles, Botanique 4: 91-144.

Mossebo, D.C. \& Antonín, V. 2004. Marasmius species (Tricholomataceae) found in man-influenced habitats in the vicinity of Yaoundé, Cameroon. Czech Mycology 56: 85-111.

Ovrebo, C.L. 1996. The agaric flora (Agaricales) of La Selva Biological Station, Costa Rica. Revista de Biologia Tropical 44: 39-57.

Pegler,D.N. 1977. A preliminary agaric flora of East Africa. Kew Bulletin Additional Series 6: 1-615.

Pegler, D.N. 1983. Agaric Flora of the Lesser Antilles. Kew Bulletin Additional Series 9: 1-668.

Pegler, D.N. 1988. Agaricales of Brazil described by M.J. Berkeley. Kew Bulletin 43: 453-473.

Pegler, D.N. 1997. The Agarics of São Paulo, Brazil. Royal Botanic Gardens, Kew. 
Petch,T. 1948. A revision of Ceylon Marasmii. Transactions of the British Mycological Society 31: 19-44.

Puccinelli, C. \& Capelari, M. 2006. Two new species of Marasmius (Marasmiaceae, Agaricales) from Brazil. Mycotaxon 95: 295-300.

Puccinelli, C. \& Capelari, M. 2007. A new species of Marasmius (Basidiomycota, Marasmiaceae) and the first record of M.foliiphilus from Brazil. Cryptogamie, Mycologie 28: 263-268.

Puccinelli, C. \& Capelari, M. 2009. Marasmius do Parque Estadual das Fontes do Ipiranga, São Paulo, SP, Brasil: seções Globulares, Hygrometrici, Marasmius e Neosessiles. Hoehnea 36: 249-258.

Silva, E.P. \& León de la Luz, J.L. 1997. Macromycetes of Baja California, Mexico. Mycotaxon 63: 395-417.

Singer, R. 1958. Studies toward a monograph of the South American species of Marasmius. Sydowia 12: 54-145.

Singer, R. 1965. Monographic studies in South American Basidiomycetes, especially those of the east slope of the Andes and Brazil 2. The genus Marasmius in South America. Sydowia 18: 106-358.

Singer, R. 1976. Marasmieae (Basidiomycetes, Tricholomataceae). Flora Neotropica 17: 1-347.
Singer, R. 1986. The Agaricales in modern taxonomy. 4 ed. Koeltz Scientific Books, Koeningstein.

Singer, R. \& Digilio, A.P.L. 1952. Pródromo de la flora Agaricina Argentina. Lilloa 25: 5-461.

Sobestiansky, G. 2005. Contribution to macromycete survey of the States of Rio Grande do Sul and Santa Catarina in Brazil. Brazilian Archives of Biology and Technology 48: 437-457.

Souza, H.Q. \& Aguiar, I.J.A. 2007. Ocorrência do gênero Marasmius Fr. (Tricholomataceae, Agaricales) na Reserva Biológica Walter Egler, Amazonas, Brasil. Acta Amazonica 37: 27-36.

Spegazzini, C. 1889. Fungi Puiggariani. Boletin de la Academia Nacional de Ciencias de Cordoba 11: 381622.

Wannathes, N., Desjardin, D.E., Retnowati, A., Tan, Y.S. \& Lumyong, S. 2004. A redescription of Marasmius pellucidus, a species widespread in South Asia. Fungal Diversity 17: 203-218. 